\title{
Research Square \\ SARS CoV 2 Nsp5 Protein Causes Acute Lung Inflammation, a Dynamical Mathematical Model
}

\section{Antonio Bensussen}

Universidad Autónoma del Estado de Morelos

José Díaz ( $\sim$ biofisica@yahoo.com )

Universidad Autónoma del Estado de Morelos

Elena R. Álvarez Buylla

Universidad Nacional Autónoma de México

\section{Research Article}

Keywords: SARS-CoV-2 infection, Interleukin 6, NFkB, Nsp5, Cox2, SARS-CoV-2 interactome, Nonlinear dynamics of inflammation

Posted Date: July 8th, 2021

DOl: https://doi.org/10.21203/rs.3.rs-348638/v1

License: (c) (1) This work is licensed under a Creative Commons Attribution 4.0 International License. Read Full License

Version of Record: A version of this preprint was published at Frontiers in Systems Biology on December 3rd, 2021. See the published version at https://doi.org/10.3389/fsysb.2021.764155. 


\section{SARS CoV 2 Nsp5 Protein Causes Acute Lung Inflammation, a Dynamical Mathematical Model}

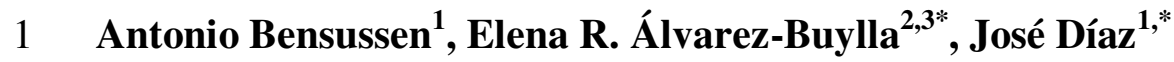

2 'Laboratorio de Dinámica de Redes Genéticas, Centro de Investigación en Dinámica Celular,

3 Universidad Autónoma del Estado de Morelos, Cuernavaca, Morelos, México.

$4 \quad{ }^{2}$ Centro de Ciencias de la Complejidad (C3), Universidad Nacional Autónoma de México, Ciudad

5 de México, México.

$6 \quad{ }^{3}$ Laboratorio de Genética Molecular, Epigenética, Desarrollo y Evolución de Plantas. Instituto de

7 Ecología, Universidad Nacional Autónoma de México, Ciudad de México, México.

17 * Correspondence:

18 José Díaz

19 biofisica@yahoo.com; jose.diaz@uaem.mx

20 Elena R. Álvarez Buylla

21 elenabuylla@protonmail.com

23 Keywords: SARS-CoV-2 infection, Interleukin 6; NFkB; Nsp5; Cox2; SARS-CoV-2 interactome;

24 Nonlinear dynamics of inflammation 
29 Abstract

30 In the present work we propose a dynamical mathematical model of the lung cells inflammation

31 process in response to SARS-CoV-2 infection. In this scenario, our model suggests that the main

32 protease Nsp5 enhances the inflammatory process by increasing the levels of NF $\kappa \mathrm{B}$, IL-6, Cox2,

33 and PGE2 with respect to a reference state without the virus. This overstimulated immune state

34 becomes autonomous of the signals from other immune cells, and does not shut down by itself

35 neither when the external signals are turned off. Our model suggests that Nsp5 is effectively the

36 switch to start inflammation, the consequent overproduction of the ACE2 receptor, and an

37 important underlying cause of the most severe cases of COVID19. 
Severe Acute Respiratory Syndrome Coronavirus 2 (SARS-CoV-2) virus is an intracellular infectious agent whose replication cycle depends on the host's cell structures and functions. In particular, it uses the translational apparatus of different types of infected cells to express its proteins (Nakagawa et al., 2016). SARS-CoV-2 causes the Coronavirus Disease 2019 (COVID19) that has infected over 117,000,000 persons and killed over 2,400,000 worldwide since the end of 2019. No specific and effective therapeutic drugs to defeat SARS-CoV-2 infection have been developed yet ${ }^{1}$, although several effective vaccines have been developed and are being applied.

SARS-CoV-2 virion is formed by four proteins: spike (S), envelope (E), membrane (M) and nucleocapside $(\mathrm{N})$ that enclose the virus genome ${ }^{2}$, which consists of a positive-sense nonsegmented single stranded mRNA ((+)ssRNA) of $30 \mathrm{~kb}$. The open reading frames 1a (orf1a) and 1b (orf1b) are located near the untranslated 5 ' region (5'UTR) of the positive single stranded RNA $((+) s s R N A)$ and they encode for the polyproteins ppla and pplab.

When SARS-CoV-2 virion infects the organism, S protein binds with high affinity to the surface receptor Angiotensin-Converting Enzyme 2 (ACE2), highly abundant in the lung alveolar type II cells and other cell types ${ }^{3,4}$, and forms a molecular complex that begins the process of fusion of the virion envelope with the host cell membrane. Finally, viral (+)ssRNA is released into the host cytoplasm $^{5}$ (Fig. 1).

The process of translation occurs in the cytoplasm and produces a set of 11 nonstructural proteins (Nsp) from the orf1a segment (Nsp1 to Nsp11), and 5 nonstructural proteins from the orf1b segment (Nsp12 to Nsp16). The set of $16 \mathrm{Nsp}$ proteins form a replication-transcription complex (RTC) where a set of nested subgenomic negative-strands of RNA ((-)sgRNA) are synthesized by discontinuous transcription, and serve as the templates for the production of subgenomic mRNAs. The structural proteins E (Envelope), M (Membrane), N (Nucleocapside) and S (Spike), and the accessory proteins orf $3 a$, orf6, orf7a, orf7b, orf8, orf9b, orf9c and orf 10 are synthesized from the subgenomic mRNAs ${ }^{1,6,7}$. SARS-CoV-2 uses the host translational machinery, and redirects it to viral protein synthesis and replication while translation of the host mRNA is inhibited ${ }^{8}$. SARS-CoV and SARS-CoV-2 genomes have $\sim 79 \%$ of homology ${ }^{9}$, and most of the set of structural and nonstructural proteins are practically the same. However, the virus species differ in the accessory proteins orf8, orf8a, orf 8b, orf9c and orf $10^{3,10}$.

Once the viral proteins are inserted into the host molecular machinery redirect a great number of host cell functions towards virus replication ${ }^{11,12}$. Gordon and collaborators experimental work on the interaction of viral and host proteins, or interactome ${ }^{3}$, has been of help to clarify how the SARSCoV-2 controls the host molecular network to replicate and propagate the infection ${ }^{13}$. From these results, is possible the construction of the undirected network representation of the interactome, and its statistical analysis indicates a modular free-scale hierarchical type of structure in which the proteins orf8, $\mathrm{N}$ and $\mathrm{Nsp} 7$ are the main hubs ${ }^{1}$.

Despite all the molecular knowledge rapidly accumulated on SARS-CoV-2 itself and the infection or inflammation processes in which it is involved in human cells, we still lack dynamical models to understand which are the key nodes underlying severe inflammation processes in some cases. Mathematical and computational dynamic network models are useful tools to integrate data, find experimental holes and also propose or understand the underlying dynamics mechanisms involved

100 in the complex viral/human networks involved during SARS-CoV-2 infection ${ }^{1,14,15,16}$. The number 
101 of nodes, the number of connections of each node to its neighbours, and the distribution of these connections in the network determine its complexity, structure and dynamical properties ${ }^{17}$.

103 In this network, the viral main protease Nsp5 has a special role in lung inflammation process through its link with Histone Deacetylase 2 (HDAC2) ${ }^{1,3,13}$ (Figs. 1 and 2); suggesting that Nsp5 represses HDAC2 inhibitory action on NF $\kappa \mathrm{B}$ (Figure 1), and thus enhances the transcription of the pro-inflammatory genes targeted by the Nuclear Factor $\kappa \mathrm{B}(\mathrm{NF} \kappa \mathrm{B})^{18}$ (Figs. 1 and 2). Such role distinguishes SARS-CoV and SARS-CoV-2. The SARS-CoV virus uses $\mathrm{N}$ protein to promote the sustained transcription of the Cyclooxygenase 2 (Cox2) enzyme by binding directly to the NF- $\kappa \mathrm{B}$ transcriptional regulatory elements, and to the CCAAT/enhancer binding proteins of the gene Cox $2^{19}$. Hence, SARS-CoV and SARS-CoV-2 produce severe acute respiratory syndrome through different molecular mechanisms.

112 The change from a hub (N protein in SARS-CoV) to a poor connected protein (Nsp5 in SARS$113 \mathrm{CoV}-2)$ as the underlying cause of severe acute respiratory syndrome could be an adaptation that made SARS-CoV-2 more pathogenic. Nsp5 is also the main protease that cleavages the SARSCoV-2 polyprotein at 11 conserved sites, and its malfunction or deletion could stop the viral replication cycle and lung inflammation ${ }^{20,21}$. Thus, Nsp5 is a molecular switch that shows a low rate of mutation $^{22}$, and its malfunctioning can decrease the strength of inflammation and the persistence of ACE2 in the lung epithelial cells giving rise to a less intense inflammatory response ${ }^{23}$.

Activation of the NF $\kappa$ B family of proteins (p65/RelA, p105/p50, p100/p52, RelB, and c-Rel) is

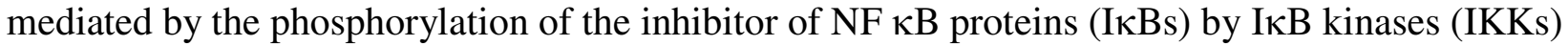
and the posterior ubiquitinylation and degradation of the phosphorylated $\mathrm{I} \kappa \mathrm{Bs}$ (Fig. 1). The released $\mathrm{NF} \kappa \mathrm{B}$ proteins enter the nucleus to activate specific genes ${ }^{18}$. In the nucleus, HDAC2 blocks the transcriptional activity of $\mathrm{NF} \kappa \mathrm{B}$, inhibiting the production and release of the cytokine Interleukin 6 (IL-6) and IKB, and interfering with the functioning of the positive feedback circuit between IL-6 and $\mathrm{NF} \kappa \mathrm{B}^{24}$ (Fig. 3A). As we mentioned before, the sustained inactivation of HDAC2 by Nsp5 produces a sustained increase in the transcriptional activity of NF $\kappa \mathrm{B}$ (Figs. 1 and 2) that leads to a high production of IL-6 in the lung epithelium cells. Release of this excess of IL- 6 to the vascular system contributes to the "cytokines storm" observed in critical patients ${ }^{25,26}$, although the average serum concentration of IL-6 in critical COVID19 patients are lower with respect to other respiratory syndromes $^{26}$. However, the uninterrupted production of IL-6 is closely associated to a persistent presence of the ACE2 receptor in the alveolar type 2 cells due to enhanced ACE2 gene expression mediated by the JAK-STAT pathway ${ }^{27}$ (Fig. 2).

$133 \mathrm{NF} \kappa \mathrm{B}$ also promotes transcription of the Cox2 gene leading to the expression and increased 134 enzymatic activity of Cox 2 (Figs. 2 and 3B). However, NF $\kappa$ B, Cox 2 and IL-6 also form a positive feedback circuit in which $\mathrm{NF} \kappa \mathrm{B}$ promotes Cox 2 enzymatic activity that catalyses the conversion of Arachidonic acid (AA) into Prostaglandin G2 (PGG2), which is in turn modified by the peroxidase moiety of the Cox 2 enzyme to produce prostaglandin $\mathrm{H} 2$ ( $\mathrm{PGH} 2$ ) that is converted to prostaglandin E2 (PGE2) ${ }^{28}$. PGE2 is then released to the vascular system, binds to its membrane $\mathrm{EP} 2$ and EP4 prostanoid receptors and promotes the cleavage of the I $\kappa \mathrm{B}-\mathrm{NF} \kappa \mathrm{B}$ complex increasing the amount of free NF $\kappa \mathrm{B}$, which increases the production of IL- $6^{29,30}$ (Fig. 3B). IL-6, in turn, increases $\mathrm{NF} \kappa \mathrm{B}$ activity $^{31}$ (Fig. 2). These regulatory circuits has three therapeutic targets: IL-6 production (Tocilizumab) ${ }^{25}$, Cox 2 (Nimesulide) ${ }^{28}$, and NF $\kappa \mathrm{B}$ (Dexamethasone) ${ }^{32,33}$. However,

144 SARS-CoV-2 infection. 
145 In this work, we propose a dynamical mathematical model that suggests that the three feedback

146 loops mentioned above constitute the minimal circuit for the inflammatory process in the epithelial lung cells during SARS-CoV-2 infection (Fig. 2), and we use an ordinary differential equations

148 (ODEs) continuous model to explore the effect of Nsp5 in the qualitative dynamics of this circuit in which this viral protein acts as an enhancing perturbation in the phase space of this dynamical system $^{34}$ (Fig. 2). For the model of the circuit, we chose as main molecular components the proteins $\mathrm{NF} \kappa \mathrm{B}, \mathrm{I} \kappa \mathrm{B}, \mathrm{IL}-6, \mathrm{Cox} 2$, and PGE2. In this model, Nsp5 prevents the movement of HDAC2 into

152 the nucleus allowing an increase in NF $\kappa \mathrm{B}$ transcriptional activity. The input that turns on the circuit in lung cells is a signal from monocytes, lymphocytes, and other immune cells that activates IL-6 production. We propose that this model represents the basic set of interactions that settles on the inflammation reaction to the invasion of the lung cells by SARS-CoV-2, and that it is a first approximation to understand the main dynamical features of this response.

\section{7}

158

159

Our hypothesis is that Nsp5 leads to the sustained overproduction of IL-6, Cox2, PGE2, and NF $\kappa \mathrm{B}$, in the epithelial lung cells, which is a necessary but not a sufficient condition for a cytokine storm. In the particular case of epithelial lung cells, we found that the computational and mathematical analysis of the model supports our hypothesis, and that Nsp5 effectively enhances NF $\kappa \mathrm{B}$, IL-6, Cox 2 and PGE2 production during the time that remains bounded to HDAC2. Furthermore, the model predicts the existence of an over stimulated immune state (OSIS) in which the amount of IL6 produced by the infected lung cells is high, and such state becomes autonomous and robust, independent of any stimulus from external sources like monocytes, and lymphocytes. Hence this OSIS cannot be completely shut down by classical anti-inflammatory drugs like Nimesulide and Dexamethasone, and can be possibly beaten only with specific inhibitors of Nsp5 like Saquinavir ${ }^{21}$.

\section{Results}

In this section we present in detail and focus on the results that are relevant to understand the role of Nsp5 in the process of acute lung inflammation. The rest of the analyses and results related to the mathematical aspects of the model are reported in the Supplementary Stability Analysis of the Model.

We solved the model using the Euler predictor-corrector method with time step of $0.05 \mathrm{~s}$ and 720,000 integration steps to simulate a period of $10 \mathrm{hrs}$ post infection, which is the estimated time for the first bursting of new virions into the extracellular medium ${ }^{17,35}$. We used the parameter values shown in Table 1 to generate an arbitrary reference state (ARS) of the system for the initial conditions $i \kappa b n f=5 \mathrm{pg} \mathrm{mL}^{-1}$, and the rest of the variables equal to 0 at time $t=0$. In this case, the input $\alpha(t)=10 \mathrm{pg} \mathrm{mL}^{-1} \mathrm{~s}^{-1}$ and $n s p 5=0$ for $t \in[0, \infty)$. In this ARS, the translation velocities ${ }^{36}$ of all genes are set to $2 \mathrm{pg} \mathrm{mL}^{-1} \mathrm{~s}^{-1}$. Fig. $4 \mathrm{~A}$ shows that the output of the model is the transitory activation of NF $\kappa \mathrm{B}, \mathrm{Cox} 2$ and PGE2, in contrast with a sustained high activation of IL-6. In order to clarify the source of the steady activation of IL-6, we solved the model with the same initial conditions and $\alpha(t)=0$. In this case, the system does not turn on during all the time of simulation (data not shown), indicating that the signal from monocytes and other cells is a necessary condition to start the IL-6 sustained production in lung cells (Fig. 4A). Fig. 4B shows that when $n s p 5 \neq 0, \alpha(t)=0$ and equal gene translation rates, the response of the system is a high sustained level of activation of $\mathrm{NF} \kappa \mathrm{B}$, Cox2, and PGE2 with respect to the ARS. In this case, the concentration of IL-6 in the cell was only slightly affected by the virus. Figs. 4A - 4D show the first five minutes of simulation during which the circuit of Fig. 2 reaches its steady state. This result indicates that the presence of the virus induce a sustained and persistent production of $\mathrm{NF} \kappa \mathrm{B}, \operatorname{Cox} 2$, and PGE2 in the circuit of Fig. 2. 
Translation rates of the set of genes of the model rarely have the same value, even when their activation is promoted by the same transcription factor (NF $\kappa \mathrm{B}$ in this case). As shown in Table 1, the results of Figs. 4A and 4B are obtained when the rates of translation are the same for all genes. However, in real cells this is not the case, and $\operatorname{Cox} 2, I l-6, N F \kappa B$ and $I \kappa B$ are translated at different rates. In Homo sapiens the estimated average rate of translation $\left(V^{\max }\right)$ of a gene is about $10^{4}$ proteins per hour ${ }^{36}$. However, this average value can be increased according to the state of activity of the cell. In the present work, we arbitrary chose the value of $V^{\max }=2 \mathrm{pg} \mathrm{mL} \mathrm{s}^{-1}$ for all genes in the ARF (Table 1). However, we made parameter variation to know how different values of this set of parameters affect the qualitative behavior of the model (see Supplementary Stability Analysis of the Model). Fig. 4C shows that when in the system $V_{n f}^{\max }=10 \mathrm{pg} \mathrm{mL}^{-1} \mathrm{~s}^{-1}, V_{I \kappa B}^{\max }=15 \mathrm{pg} \mathrm{mL} \mathrm{m}^{-1}$, $V_{C o x 2}^{\max }=2 \mathrm{pg} \mathrm{mL}^{-1} \mathrm{~s}^{-1}$, and $V_{I L 6}^{\max }=2 \mathrm{pg} \mathrm{mL}^{-1} \mathrm{~s}^{-1}, \alpha(t)=10 \mathrm{pg} \mathrm{mL}^{-1} \mathrm{~s}^{-1}$ and $n s p 5=0$, the circuit tends to a steady state in which NF $\kappa \mathrm{B}$, Cox2, and PGE2 exhibit a constant low concentration during the time of simulation, while IL-6 steady concentration is unaffected with respect to the value shown in Fig. 4A. When $n s p 5 \neq 0$, the steady concentration of $\mathrm{NF} \kappa \mathrm{B}$, and Cox 2 , are increased $\sim 10$ fold with respect to their maximum concentration in the ARS, while PGE2 concentration is increased $\sim 4$ fold; Nsp5 produces a 4 fold decrease in IL- 6 steady concentration with respect to the reference concentration shown in Fig. 4A. This result indicates that a the difference in translation rates between $N F \kappa B$ and $I \kappa B$ (the intensity of the inhibition of $N F \kappa B$ by $I \kappa B$, Fig. 3A) in absence of the virus with respect to their values in ARS induces a low sustained production of $\mathrm{NF} \kappa \mathrm{B}$, Cox2, and PGE2 without affecting IL-6 production. However the presence of Nsp5 induces a high production of NF $\kappa \mathrm{B}$ and Cox2, and a moderate increase in PGE2 concentration that decreases IL-6 concentration, indicating that a higher rate of I $\kappa$ B translation with respect to $N F \kappa B$ translation can decrease the concentration of the cytokine IL-6 in presence of the virus probably due to a lower concentration of PGE2in the circuit (Figs. 2 and 3A).

Fig. 4D shows that when $\alpha(t)=10 \mathrm{pg} \mathrm{mL}^{-1} \mathrm{~s}^{-1}, n s p 5=0, V_{n f}^{\max }=10 \mathrm{pg} \mathrm{mL}^{-1} \mathrm{~s}^{-1}, V_{I \kappa B}^{\max }=15 \mathrm{pg} \mathrm{mL}^{-1} \mathrm{~s}^{-1}$ , $V_{\text {Cox } 2}^{\max }=2 \mathrm{pg} \mathrm{mL} \mathrm{s}^{-1} \mathrm{~s}^{-1}$, and $V_{I L 6}^{\max }=20 \mathrm{pg} \mathrm{mL}^{-1} \mathrm{~s}^{-1}$ the circuit tends to a steady state in which $\mathrm{NF} \kappa \mathrm{B}$, Cox 2 and PGE2 exhibit a constant low concentration during the time of simulation, while IL-6 is unaffected with respect to its steady concentration in Fig. 4A. However, when $n s p 5 \neq 0$ the dynamical behavior of the circuit changes because NF $\kappa \mathrm{B}$ and Cox 2 show the same steady concentration that in Fig. 4C, but PGE2 has a higher steady concentration. In this case, IL-6 shows an increase of $\sim 2$ fold with respect to the level shown in Fig. 4C. Thus, a high rate of IL-6 translation can overcome the effect of an increased rate of I $\kappa B$ translation in presence of the virus, allowing an overproduction of the cytokine.

All these results suggest an important dynamical property of the circuit shown in Fig. 2: a high value of the parameter $V_{I L 6}^{\max }$ produces an over production of $\mathrm{NF} \kappa \mathrm{B}, \mathrm{Cox} 2$, PGE2, and IL-6 in the circuit in presence of Nsp5 with respect to the ARS (Figs. 4A and 4D). We name over stimulated immune state (OSIS) to the state of the system shown in Fig. $4 \mathrm{D}$, for which: $V_{n f}^{\max }=10 \mathrm{pg} \mathrm{mL} \mathrm{m}^{-1}$, $V_{I \kappa B}^{\max }=15 \mathrm{pg} \mathrm{mL}^{-1} \mathrm{~s}^{-1}, V_{C o x 2}^{\max }=2 \mathrm{pg} \mathrm{mL}^{-1} \mathrm{~s}^{-1}, V_{I L 6}^{\max }=20 \mathrm{pg} \mathrm{mL}^{-1} \mathrm{~s}^{-1}, n s p 5 \neq 0$ and $\alpha(t)=10 \mathrm{pg} \mathrm{mL}^{-1} \mathrm{~s}^{-1}$.

Fig. 5 shows the response of the circuit to a step function defined as:

$$
\alpha(t)=\left\{\begin{array}{cc}
10 & 0 \leq t<10 \\
0 & t>10
\end{array}\right.
$$


The latter simulates an external signal of IL-6 initially generated at a rate of $10 \mathrm{pg} \mathrm{mL}^{-1} \mathrm{~s}^{-1}$ during 10 minutes, and switched off after the 10 minutes. Fig. 5A is the response of the system in ARS to the step signal, in absence and presence of Nsp5. Interestingly, in the absence of Nsp5, the circuit exhibits a low concentration of NF $\kappa B$, Cox 2 and PGE2, and a high concentration of IL-6, all which are zero when the external signal is switched off. In presence of Nsp5 the ARS is perturbed by $\alpha(t)$, and reaches a new steady state with high concentrations of NF $\kappa B$, Cox2, and PGE2 that remain even when the external signal is switched off. Furthermore, the high IL-6 concentration reached when the circuit is turned on falls to a lower concentration different from zero when $\alpha(t)=0$.

Fig. 5B is the response of the circuit in OSIS to the step function. In absence of Nsp5, the circuit exhibits a low concentration of NF $\kappa B$, Cox2 and PGE2, and a high concentration of IL-6, all which are zero when the external signal is switched off. However, in presence of Nsp5 the OSIS is perturbed by $\alpha(t)$, and reaches a new steady state with high concentrations of NF $\kappa \mathrm{B}$, Cox 2 , and PGE2 that remain even when the external signal is switched off. Furthermore, the higher IL-6 concentration reached when the circuit is turned on only falls $\sim 50 \%$ of its maximum concentration when $\alpha(t)=0$. These results suggest that the OSIS becomes autonomous of the external signal generated by monocytes and other immune cells in presence of Nsp5, i.e., the OSIS becomes a persistent state in presence of SARS-CoV-2, and never shut down by itself or by removing external signaling during the 10 hrs of simulation.

In order to reduce the effect of Nsp5 on the circuit of Fig. 2, we tested the effect of Nimesulide on $\mathrm{NF} \kappa \mathrm{B}$ production. Nimesulide, a Cox 2 inhibitor, acts inhibiting the synthesis of Cox 2 and lipooxigenase enzyme and their products ${ }^{37}$. We modified Eq. (14) to introduce an inhibition term that decreases the rate of production of Cox 2 in presence of Nimesulide:

$$
\frac{d \operatorname{cox} 2}{d t}=\frac{V_{\operatorname{cox} 2}^{\max } p_{\operatorname{cox} 2}^{o n}(t)}{n i m+1}-k_{10} \operatorname{cox} 2
$$

where nim is the amount of Nimesulide at time $t$, whose rate of variation of its concentration in the cell is:

$$
\frac{d(\operatorname{nim})}{d t}=r_{2}-k_{19} \text { nim }
$$

where $r_{2}=40 \mathrm{pg} \mathrm{mL}^{-1} \mathrm{~s}^{-1}$ and $k_{19}=3 \mathrm{~s}^{-1}$. Solution of the modified model (Eq. 17) is presented in Fig. 6. In Fig. 6A, Nimesulide is applied to the circuit in presence of Nsp5, and with all gene translation rates set to $2 \mathrm{pg} \mathrm{mL}^{-1} \mathrm{~s}^{-1}$. In this case, Nimesulide has no effect on $\mathrm{NF} \kappa \mathrm{B}$, a slightly effect on IL-6, and a significant decrease in Cox 2 and PGE2 concentrations to values near to zero in presence of 14 $\mathrm{pg} \mathrm{mL} \mathrm{L}^{-1}$ of the drug. The same effect is observed when the circuit is in OSIS (Fig. 6B). Thus, Nimesulide is not an effective anti-inflammatory agent in the context of the dynamic circuit modeled here, and does not impact the concentration of IL-6 in the presence of Nsp5, even at high concentrations.

Dexamethasone (DX), is a potent synthetic glucocorticoid that inhibits NF $\kappa B$ transcription, and is another anti-inflammatory drug that is being used to ameliorate acute inflammatory states due to SARS-CoV-2 infection. In order to test the effect of DX on the inflammatory process in the circuit of Fig. 2, we modified Eq. (8) to introduce an inhibition term that decreases the probability of activation of $N F \kappa B$ : 
$\frac{d p_{N F \kappa B}^{o n}(t)}{d t}=k_{15}\left(\frac{n f^{*}}{\left(h d^{*}+1\right)(D X+1)}\right)\left(1-p_{N F \kappa B}^{o n}(t)\right)-k_{-15} p_{N F \kappa B}^{o n}(t)$

where $D X$ is the amount of $\mathrm{DX}$ at time $t$, whose rate of variation of its concentration in the cell is:

270

$$
\frac{d(D X)}{d t}=r_{3}-k_{20} D X
$$

where $r_{3}=30 \mathrm{pg} \mathrm{mL}^{-1} \mathrm{~s}^{-1}$ and $k_{20}=3 \mathrm{~s}^{-1}$.

Fig. 7 shows the effect of DX on the circuit. Fig. 7A shows that when DX is applied to the circuit in presence of Nsp5, and when all genes have the same translation rate of $2 \mathrm{pg} \mathrm{mL}^{-1} \mathrm{~s}^{-1}$, the drug eliminates NF $\kappa B$, Cox 2 and PGE2 from the circuit, but has a null effect on the concentration of IL6. However, when the circuit is in OSIS (Fig. 7B), DX has little effect on the immune response in presence of Nsp5. Fig. 7C shows that when all translation rates are the same $\left(2 \mathrm{pg} \mathrm{mL}^{-1} \mathrm{~s}^{-1}\right), \mathrm{DX}$ can shut down the immune response in presence of the virus, when the circuit input $\alpha(t)$ is the function of Eq. (16). However, DX cannot shut down the effects of Nsp5 when the circuit is in OSIS, having a little anti-inflammatory effect (Fig. 7D). Hence, our results suggest that DX is an effective antiinflammatory drug during mild inflammatory states, but is less effective during critical acute lung inflammation due to SARS-CoV-2 $2^{38}$. This dynamical behavior of the circuit of Fig. 2 is unaffected by higher doses of DX. When DX and Nimesulide are applied together (with $35 \mathrm{pg} \mathrm{mL}^{-1}$ of DX and $40 \mathrm{pg} \mathrm{mL}^{-1}$ of Nimesulide) to the circuit in OSIS, in which $\alpha(t)$ is the function of Eq. (16), there is also a limited anti-inflammatory effect (Fig. 8A).

285 In contrast, the predicted limited effect of Nimesulide and DX on reverting the OSIS, the molecular inflammation. We tested this hypothesis modifying Nsp5 production in Eq. (11) with an inhibitory term:

$\frac{d(n s p 5)}{d t}=\frac{\phi}{d r u g+1}-k_{18} n s p 5$

290 where drug is the amount of the hypothetical drug that can remove Nsp5 from the circuit, whose

$\frac{d(d r u g)}{d t}=r_{4}-k_{21} d r u g$

with $r_{4}=30 \mathrm{pg} \mathrm{mL}^{-1} \mathrm{~s}^{-1}$ and $k_{21}=3 \mathrm{~s}^{-1}$.

Fig. 8B shows that when the hypothetical drug is applied to the circuit in OSIS, with $\alpha(t)$ given by

295 Eq. (16), the inflammatory process is completely shut down, suggesting that Nsp5 is effectively the

296 key cause of the acute lung inflammation during SARS-CoV-2 infection, and a fundamental

297 potential target for its treatment. 
301 The complexity of the immune response to infections implies a complex set of different kinds of

302 cells that involve complex regulatory networks and molecules. Together, they underlie specific

303 responses that may lead to resolution or to inflammatory responses whose dynamical properties

304 depend on the networks structure (i.e., the number of nodes, links, and the distribution of links

305 between the nodes) occurring at different scales and levels ${ }^{39,40}$. The structure of such complex and

306 dynamical network is not random due to the specific nature of its nodes and links, so that if the

307 network has a hierarchical structure its hubs determine the overall network dynamics and the

308 structure of its phase space ${ }^{34,39,41}$. In high dimensional phase spaces, steady points of diverse kinds

309 can coexist with isolated closed curves (limit cycles), strange attractors of fractal structure, and

310 other limit sets giving rise to a variety of biological dynamical behaviors like molecular switches,

311 periodic and quasi-periodic oscillations, and bursting (among others). Two central problems in the

312 analysis of this kind of dynamical systems are: a) the structure of the phase space is strongly

313 dependent of the value of the set of parameters of the dynamical system, and b) the nonlinearity

314 characteristic of biological systems such as the one treated here ${ }^{42}$ (see Supplementary Introduction

315 to Nonlinear Dynamics).

316 In most of the ODEs-based biological models so far studied, there is limited knowledge of the real

317 values of the parameters, and this leads to uncertainty concerning the extent to which the model

318 explains the real process under study. In this case, the validation of the model relied on

319 experimental data. Nonetheless, with the exception of some particular cases ${ }^{43}$, qualitative models

320

321

322

323

324

325

326

327

328

329

330

331

332

333

334

335

336 have to be proposed and quantitative validations remain ahead ${ }^{39}$. This challenge increases with the dimensionality of the model. Thus, is necessary to choose some particular properties of the network under study (inflammation network in this case) that incorporate key dynamical features of the whole system under study, and that can also aid to reduce the number of parameters of the model to the minimum possible.

In this sense, we limited the scope of this work to the study of the inflammation process of epithelial lung cells during SARS-CoV-2 infection. The epithelial lung cells form a sub-network that have two highly connected nodes: the internal signal integrator $\mathrm{NF} \kappa \mathrm{B}$, and the external signal integrator IL-6 Receptor (IL6R) ${ }^{25}$, which is activated by external IL-6 (Figs. 2 and 3). Both integrators trigger the activation of two important intermediate processes: Cox 2 and PGE2 synthesis. Thus, we propose, as a first approximation, that the dynamical behavior of this these four nodes of the circuit of Fig. 2 reflect with certain accuracy the dynamical properties of the complex inflammation sub-network of lung cells. Thus, the dynamics of IL-6, NF $\kappa B$, Cox 2 and PGE2 nodes is described by a model that consist of 12 nonlinear coupled ordinary differential equations (Table 1), that we assume represents the central dynamical core involved in the lung cells inflammation process in response to SARS-CoV-2 infection. Such core includes three coupled feedback loops shown in Fig. 3. We used this low-dimensionality model to explore the effect of Nsp5 in the qualitative dynamics of the inflammation circuit of Fig. $2^{17,34}$.

338 SARS-CoV-2 main protease Nsp5 has a role as an epigenetic regulator of host DNA expression in lung cells; and thus its physical association with HADC2 $2^{3,17}$ avoids the movement of the deacetylase from the cytoplasm to the nucleus, increasing the probability of the binding of NF $\kappa \mathrm{B}$ to the promoter site of its target genes ${ }^{44}$ (Eqs. 5-8). NF $\kappa \mathrm{B}$ is a central integrator of the signals that initiate the inflammation process (Fig. 1), which include IL-6 secreted by monocytes, leucocytes, macrophages, among other cells, together with signals from TLR4 and TLR7 that suppress the IкB$\mathrm{NF} \kappa \mathrm{B}$ complex in a MyD88 independent manner ${ }^{45}$. NF $\kappa \mathrm{B}$ enhanced transcriptional activity 
345 includes the transcription of $I L-6, \operatorname{Cox} 2, I \kappa B$ and $N F \kappa B$ itself that are key genes in the process of 346 inflammation (Fig. 3).

347 Results obtained from our model suggest that Nsp5 can effectively transform a weak inflammation 348 response into a persistent sustained one that has a relative high concentration of the cytokine IL-6 (Fig. 4B). In the example of Fig. 4B, all genes have the same translation rate, a condition that have low probably of occurrence in the real human immune system in which every gene is subject to different processes of post transcriptional regulation ${ }^{36}$. When this restriction is removed, and IL-6 has a high translation rate, Nsp5 boosts the concentration of the four main proteins of the circuit with respect to their respective values in ARS, and the inflammation response becomes strongly persistent with a high IL-6 concentration. Furthermore, in this state that we named OSIS, the dynamics of the circuit of Fig. 2 becomes independent of any kind of external signal and never turns off, leading to the deregulation of the production of the cytokine IL-6 (Fig. 5B). In this form, Nsp5 changes the qualitative dynamical behavior of the system, in which the trajectories that initially span around the ARS stable node now span around the OSIS stable node ${ }^{34}$ (see Supplementary Stability Analysis of the Model).

An important biological consequence of this change in the qualitative dynamics of the circuit is that ACE2 receptor synthesis also becomes persistent and autonomous of any external signal to the lung cells (Fig. 2). Furthermore, neither Nimesulide nor Dexamethasone or both can eliminate the OSIS suggesting that this dynamical behavior could be the form in which the virus assures the persistence of its reproductive cycle without any perturbation from the natural defenses of the body. This can be also a possible clue about the possible adaptive substitution of $\mathrm{N}$ protein used in SARS-CoV for the use of the main protease Nsp5 in SARS-CoV-2 as the switch for the inflammation process, which is necessary for ACE2 sustained production, taking into consideration that SARS-CoV N protein targets Cox 2 while SARS-CoV-2 Nsp5 protein targets the master integrator NF $\kappa \mathrm{B}$. If this hypothesis is true, this is the probable cause of the increased pathogenicity of SARS-CoV-2 with respect to SARS-CoV.

371 It is of interest that the persistence of the OSIS is supported by a high translational rate of $I L-6$, 372 which in the model must have a value of $V_{I L 6}^{\max } \geq 7 \mathrm{pg} \mathrm{mL}^{-1} \mathrm{~s}^{-1}$. This result pictures a probable hypothetical scenario where the external signal $\alpha(t)$ triggers the initial inflammation response with a low translation rate of IL-6 that can be shut down with DX. As viral infection continues, IL-6, NF $\kappa \mathrm{B}$, and $\mathrm{I} \kappa \mathrm{B}$ increase their rate of translation ( $V_{C \times x 2}^{\max }$ value has a little weight in this process) and the dynamical behavior of the circuit of Fig. 2 becomes independent of the value of $\alpha(t)$, and selfsustained, i.e., the control of the production of the cytokine IL-6 is translated from the external immune cells to the lung cells, and cannot be stopped even with high doses of DX. In this form, in the model, $V_{I L 6}^{\max }$ is a bifurcation parameter that changes the qualitative dynamical behavior of the

380 circuit of Fig. 2 when $V_{n f}^{\max }=10 \mathrm{pg} \mathrm{mL}^{-1} \mathrm{~s}^{-1}$ and $V_{I \kappa B}^{\max }=15 \mathrm{pg} \mathrm{mL}^{-1} \mathrm{~s}^{-1}$ are constant values (see Supplementary Stability Analysis of the Model).

382 In this extreme situation (OSIS), the unique treatment possible suggested by our model is an 383 inhibitor of Nsp5 like Saquinavir ${ }^{21}$. In this case, the OSIS is completely shut down, which indirectly 384 implies the down production of ACE2. Saquinavir is an anti-retroviral drug used against the main protease of $\mathrm{HIV}-1^{21,46}$, with some undesirable effects like diarrhea, abdominal pain, and nausea. We suggest that this drug could be a plausible treatment against the effects of SARS-CoV-2 in acute lung inflammation, and as a complement to the new vaccine against this coronavirus. 
In a previous work ${ }^{1}$ the role of the viral protein Orf8 as a hub of the SARS-CoV-2 infection was suggested. This highly connected protein has as main targets those processes related to the vesicular trafficking required for the ensemble of new virions ${ }^{3}$ (Fig. 1). Thus, the inhibition of the effects of Orf8 in the host cells could block the reproduction cycle of the virus but not the inflammation process because Nsp5 is not directly linked to Orf $8^{3}$. Rapamycin has been suggested as a drug against the effects of Orf8 but produces severe immunosuppressant effects, which, according to the results of our model, will not be of care in cases of severe lung inflammation because Nsp5 uncouple the circuit of Fig. 2 from the process of viral replication (Figs.1 and 5B). In this case, a treatment with Rapamycin and Saquinavir can be an alternative for patients with severe lung inflammation. This suggestion needs experimental verification and clinical evaluation.

\section{Conclusions}

In this work we propose a dynamical model that puts forward a novel hypothetical mechanisms underlying lung cells inflammation process in response to SARS-CoV-2. In this scenario the main protease Nsp5 effectively enhances the inflammatory process, increasing the levels of NF $\kappa B$, IL-6, Cox2, and PGE2 with respect to the reference state. When the translation rates of NF $\kappa B$ and IкB are increased to a high constant value, and the translation rate of IL-6 is increased above the threshold value of $7 \mathrm{pg} \mathrm{mL}^{-1} \mathrm{~s}^{-1}$ the circuit enters in a persistent over stimulated immune state (OSIS) with high levels of the cytokine IL-6. The OSIS never shuts down by itself, and becomes autonomous of the signals from other immune cells like macrophages and lymphocytes. Our model explains why DX or Nimesulide have little effect on the OSIS, and the only means to suppress such acute and sustained inflammation state is by inhibiting the protein Nsp5 with drugs such as Saquinavir.

In this form, the model suggests, in accordance to our hypothesis, that Nsp5 is effectively a key node underlying severe acute lung inflammation during SARS-CoV-2 infection. The persistent production of IL-6 by lung cells during infection can be one of the causes of the cytokine storm observed in critical patients with COVID19. From an evolutionary point of view, the use of Nsp5 as the switch to start inflammation, and the consequent overproduction of the ACE2 receptor, could have driven the increased pathogenicity of SARS-CoV-2 with respect to SARS-CoV.

The present theoretical work is part of the project "Dynamics of the SARS-CoV-2 network" and is based on the experimental data reported in the literature at the moment.

\section{Model}

419 Immune response to infections involves complex spatio-temporal processes involving multiple molecular components, non-linear interactions and cell-cell interactions. In consequence, the immune response to infections is a multidimensional, multiscale and multilevel dynamical process in which innate and acquired immunity mechanisms are involved to protect the organism against pathogens ${ }^{39}$. In this scenario, the number of variables that become both sufficient and necessary for a detailed enough description of the spatio-temporal dynamics of the immune system is tremendously high. Some computational integrative efforts have been made in this direction ${ }^{47}$, but imply very large systems that cannot be modeled with continuous quantitative models that are, in turn, necessary if we want to understand which are key nodes driving the system towards the OSIS. The lack of quantitative experimental data and knowledge of the values of most of the model parameters are additional challenges to achieve such dynamic models of the immune system in 
response to specific infectious diseases. Thus, most models of the immune system have been qualitative $\mathrm{e}^{39,48}$.

432 A possible approach implies the use of ordinary differential equations (ODEs) qualitative modeling that is oriented to determine all the possible trajectories of a dynamical system along its $n$ dimensional phase space (with $n>0$ ), when the system is subject to a set of initial conditions and parameters values. High dimensional nonlinear dynamical systems can exhibit a variety of coexisting dynamical behaviors that determine the structure of their phase space ${ }^{49}$. However, the structure of the phase space of biological nonlinear dynamical systems is highly dependent on the set of parameters values. Variations in the value of one or more parameters can drive a drastic change in phase space generating a different qualitative dynamics of the system. This process is known as bifurcation, and it is important to find the possible bifurcations in the system and to identify which parameter or parameters are the responsible of these changes ${ }^{49}$ (See Supplementary Introduction to Nonlinear Dynamics).

443 In order to avoid the problem due to the high dimensionality and complexity of the immune response to SARS-CoV-2 infection, and to use the minimum number of parameters in the model that we are proposing in this work, we assume that the interaction between nodes IL- $6, \mathrm{NF} \kappa \mathrm{B}, \mathrm{I} \kappa \mathrm{B}$, Cox 2 and PGE2 settles on the main dynamical features of the inflammation process in lung epithelial cells due to the presence of the Nsp5 viral protein. In the proposed circuit shown in Fig. 2, IL-6, NF $\kappa$ B, Cox 2 and PGE2 define three feedback loops (Figs. 3A and 3B): a positive feedback loop between NF $\kappa$ B and IL-6 (Fig. 3A); a positive feedback loop between NF $\kappa$ B and I $\kappa$ B (Fig. 3A); and a negative feedback loop between PGE2 and IאB (Fig. 3B).

451 These feedback loops are distributed between three compartments:

a) IL-6 is secreted into the extracellular medium where it acts in paracrine and exocrine form. IL-6 binds to its receptor IL6R at the cell surface. Once the complex IL6-IL6R is formed, it activates IKK in the cytoplasm ${ }^{31}$. PGE2 is also secreted into this compartment where it binds to EP2 and EP4 receptors at the cell surface, activating Protein Kinase B (Akt) in the cytoplasm ${ }^{29}$.

456 b) IKK, free NF $\kappa \mathrm{B}$, and the complex I $\kappa \mathrm{B}-\mathrm{NF} \kappa \mathrm{B}$ are located in the cytoplasm, where I $\mathrm{B}$ is 457 degraded by ubiquitination. Protein Cox 2 is located in the endoplasmic reticulum (ER).

458 c) Free $N F \kappa B$ enters the nucleus where induce the transcription of $I L 6, \operatorname{Cox} 2, I K B$ and $N F \kappa B$ 459 genes. Transcriptional activity of nuclear NF $\kappa \mathrm{B}$ is inhibited by HDAC2, and enhanced by Nsp5.

460 In this form, the model cell consists of three compartments: extracellular medium, cytoplasm and 461 nucleus. We assume that the ratio of the cytoplasmatic volume to external volume $\left(V_{c y t} / V_{\text {out }}\right)$ is 462 one, and that the radio of the cytoplasmatic volume to the nuclear volume $\left(V_{c y t} / V_{n u c}\right)$ is 2 . In each 463

464 In the circuit of Fig. 2, the rate of production of free cytoplasmic NF $\kappa \mathrm{B}$ depends on the rate of its 465 release from the I $\kappa \mathrm{B}-\mathrm{NF} \kappa \mathrm{B}$ complex, which is proportional to the product of the concentrations of 466 I $\kappa$ B and IKK (Fig. 3A), its own rate of production due to nuclear NF $\kappa$ B transcriptional activity 467 inhibited by HDAC2 (Figs. 1 and $3 \mathrm{~A}$ ), the rate at which is recaptured by $\mathrm{I} \kappa \mathrm{B}$ (Fig. $3 \mathrm{~A}$ ), and the rate 468 of transport into the nucleus: 
$469 \quad \frac{d(n f)}{d t}=V_{n f}^{\max } p_{n f}^{o n}(t)+k_{a} i k k \cdot i \kappa b n f-k_{4} n f \cdot i \kappa b-D \cdot n f$

470 where $n f$ is the concentration of free cytoplasmic $\mathrm{NF} \kappa \mathrm{B}, V_{n f}^{\max }$ is the maximum rate of translation of 471 the NF $\kappa \mathrm{B}$ gene, $p_{n f}^{o n}(t)$ is the probability that the NF $\kappa \mathrm{B}$ gene is in its active state (on), $i k k$ is the 472 concentration of IKK, $i \kappa b n f$ is the concentration of I $\kappa \mathrm{B}-\mathrm{NF} \kappa \mathrm{B}$ complex, $k_{a}$ and $k_{2}$ are rate constants 473 and $D$ is the transport constant (Table 1).

474 We assume that the concentration of IKK activated by IL-6 is proportional to the external 475 concentration of the cytokine: $i k k=\gamma_{1} \cdot i l 6$, where $\gamma_{l}$ is a constant of proportionality. In a similar 476 form, PGE2 increases the rate of cleavage of the complex I $\kappa \mathrm{B}-\mathrm{NF} \kappa \mathrm{B}$ by phosphorylation of the 477 IKK $\alpha$ subunit by $\mathrm{Akt}^{50}$ (Fig. 3B). Thus, we assume that the concentration of Akt is proportional to 478 the external concentration of PGE2: $a k t=\gamma_{2} \cdot p g e 2$. Substituting both expressions in Eq. (1) we 479 finally obtain:

$\frac{d(n f)}{d t}=V_{\max n f} p_{n f}^{o n}(t)+k_{1} i l 6 \cdot i \kappa b n f+k_{11} p g e 2 \cdot i \kappa b n f-k_{4} n f \cdot i \kappa b-D \cdot n f$

481 where $k_{1}$ and $k_{11}$ are the new rate constants (Table 1).

482 The rate at which the complex I $\kappa \mathrm{B}-\mathrm{NF} \kappa \mathrm{B}$ is broken in presence of IKK depends on the rate at 483 which IKK and Akt remove IKB from the complex under the action of IL-6 and PGE2, and the rate 484 at which the complex is formed again.:

$$
\frac{d(i \kappa b n f)}{d t}=k_{4} n f \cdot i \kappa b-k_{5} i l 6 \cdot i \kappa b n f-k_{11} p g e 2 \cdot i \kappa b n f
$$

where $i \kappa b n f$ is the concentration of the complex I $\kappa \mathrm{B}-\mathrm{NF} \kappa \mathrm{B}$, and $k_{4}$ and $k_{5}$ are rate constants (Table $1)$.

The rate at which $\mathrm{NF} \kappa \mathrm{B}$ enter the nucleus depends on the rate of transport of the molecule into de nucleus, adjusted for the change in volume between the cytoplasmic and nuclear compartments, and on the rate of inhibition of nuclear $\mathrm{NK} \kappa \mathrm{B}$ by its inhibitors:

$\frac{d n f *}{d t}=D\left(\frac{V_{c y t}}{V_{\text {nuc }}}\right) n f-k_{\mathrm{deg}} n f *$

492 where $n f^{*}$ is the nuclear concentration of $\mathrm{NF} \kappa \mathrm{B}$ and $k_{d e g}$ is a rate constant.

493 The probabilities of activation of genes $I L 6, \operatorname{Cox} 2, I \kappa B$ and $N F \kappa B$ (Figs. 3A and 3B) are given by: 494

$$
\frac{d p_{I L 6}^{o n}(t)}{d t}=k_{2}\left(\frac{n f^{*}}{h d^{*}+1}\right)\left(1-p_{I L 6}^{o n}(t)\right)-k_{-2} p_{I L 6}^{o n}(t)
$$


495

$$
\frac{d p_{I \kappa B}^{o n}(t)}{d t}=k_{3}\left(\frac{n f^{*}}{h d^{*}+1}\right)\left(1-p_{I \kappa B}^{o n}(t)\right)-k_{-3} p_{I \kappa B}^{o n}(t)
$$

496

$$
\frac{d p_{C o x 2}^{o n}(t)}{d t}=k_{7}\left(\frac{n f^{*}}{h d^{*}+1}\right)\left(1-p_{C o x 2}^{o n}(t)\right)-k_{-7} p_{C o x 2}^{o n}(t)
$$

$$
\frac{d p_{N F \kappa B}^{o n}(t)}{d t}=k_{15}\left(\frac{n f^{*}}{h d^{*}+1}\right) \cdot\left(1-p_{N F \kappa B}^{o n}(t)\right)-k_{-15} p_{N F \kappa B}^{o n}(t)
$$

see Supplementary Master Equation for Gene Activation for the mathematical deduction of these equations. For Eq. 5-7, the variable $p_{i}^{o n}(t)$, with $i \in\{\mathrm{IL}-6, \mathrm{I} \kappa \mathrm{B}, \mathrm{Cox} 2, \mathrm{NF} \kappa \mathrm{B}\}$, is the probability that the gene $i$ is expressed at time $t, h d^{*}$ is the amount of HDCA2 in nucleus, and $k_{2}, k_{-2}, k_{3}, k_{-3}, k_{7}$,

$501 \mathrm{k}_{-7}, k_{15}, k_{-15}$ are rate constants (Table 1 ).

502 We assume that free cytoplasmic HDAC2 is produced according to the rate equation:

503

$$
\frac{d(h d)}{d t}=\frac{r}{\eta(n s p 5+1)}-D_{2} \cdot h d
$$

where $h d$ is the amount of free cytoplasmic HDAC2 that is produced at a constant rate $r, D_{2}$ is the rate of transport of free HDAC2 into the nucleus. In this equation, $n s p 5$ is the amount of Nsp5 in the infected cell that sequester HDAC2 in cytoplasm ${ }^{44}$, and $\eta$ is a constant (Table 1). Free cytoplasmic HDCA2 enters the nucleus according to the equation:

$\frac{d\left(h d^{*}\right)}{d t}=D_{2}\left(\frac{V_{c y t}}{V_{n}}\right) h d-k_{\operatorname{deg} 2} h d^{*}$

where $h d^{*}$ is the amount of HDAC2 in the nucleus, and $k_{d e g}$ is a rate constant (Table 1 ).

Nsp5 is a protein with only one link in the virus interactome ${ }^{1,3,13}$, which is an input to the circuit of

511 Fig. 2. However, the real kinetic mechanism of production of this viral protein is unknown, thus we

512 assume a plausible simple kinetic mechanism that leads Nsp5 to have a maximum constant

513 concentration of $20 \mathrm{nM}$. We set the parameters $\phi$ and $k_{18}$ to the values shown in Table 1 :

$514 \quad \frac{d(n s p 5)}{d t}=\phi-k_{18} n s p 5$

where $\phi$ is the constant rate of production of Nsp5, and $k_{18}$ is a rate constant (Table 1). The effect of the variation of parameter $\phi$ on the dynamics of the circuit of Fig. 2 is analyzed in the Supplementary Stability Analysis of the Model.

518 During the early stage of infection by SARS-CoV-2, the rate of variation of the concentration of IL5196 outside the lung cell depends on the rate of production of IL- 6 by monocytes, leucocytes and other 
522

523

524

525

$$
\frac{d(i l 6)}{d t}=\alpha(t)+V_{I L 6}^{\max } p_{I L 6}^{o n}(t)-k_{5} i l 6 \cdot i \kappa b n f-k_{6} i l 6
$$

526 where $V_{I L 6}^{\max }$ is the maximum rate of translation of $I L 6, p_{I L 6}^{o n}(t)$ is the probability that the $I L 6$ gene is activated at time $t$, and $k_{5}$ and $k_{6}$ are rate constants (Table 1).

528 The rate of variation of the amount of free IкB in the system is the balance between the rate of 529 translation of gene $I \kappa B$ and the rate of formation of new I $\kappa \mathrm{B}-\mathrm{NF} \kappa \mathrm{B}$ complexes:

$530 \quad \frac{d(i \kappa b)}{d t}=V_{I \kappa B}^{\max } p_{I \kappa B}^{o n}(t)-k_{4} i \kappa b \cdot n f$

531 where $V_{I \kappa B}^{\max }$ is the maximum rate of translation of $I \kappa B$, and $p_{I \kappa B}^{o n}(t)$ is the probability that the gene $532 I \kappa B$ is activated at time $t$ (Table 1 ).

533 The rate of variation of the amount of the enzyme Cox 2 in the system depends on the rate of 534 translation of the Cox 2 gene, and its rate of inhibition by different mechanisms:

$535 \quad \frac{d \operatorname{cox} 2}{d t}=V_{\operatorname{Cox} 2}^{\max } P_{C o x 2}^{o n}(t)-k_{10} \operatorname{cox} 2$

536 where $\operatorname{cox} 2$ is the amount of the enzyme in the system, $V_{\operatorname{Cox} 2}^{\max }$ is the maximum rate of variation, $537 p_{C o x 2}^{o n}(t)$ is the probability that the gene Cox2 is activated at time $t, k_{8}, k_{9}$ and $k_{10}$ are rate constants 538 (Table 1).

539 The rate of variation of the amount of PGE2 in the system depends on the amount of Cox2, on the 540 amount of IL-6, and on its rate of degradation:

$541 \frac{d p g e 2}{d t}=k_{17} \operatorname{cox} 2-k 11$ pge $2 \cdot i \kappa b n f-k_{12}$ pge 2

542 where $k_{11}, k_{12}$ and $k_{17}$ are rate constants (Table 1).

\section{Conflict of Interest}

544 The authors declare that the research was conducted in the absence of any commercial or financial 545 relationships that could be construed as a potential conflict of interest.

\section{$546 \quad 7 \quad$ Author Contributions}

547 Antonio Bensussen made the stability and sensitivity analysis of the model. Elena R. Álvarez548 Buylla and José Díaz conceived the study, discussed the data, and wrote the paper. José Díaz 549 coordinated the study. 


\section{$550 \quad 8 \quad$ Funding}

551 This work was supported by CONACYT. Antonio Bensussen was supported by a CONACYT

552 Postdoctoral grant.

5539 Acknowledgments

554 José Díaz thanks Erika Juarez Luna for logistical support.

55510 Supplementary Material

556 Supplementary Stability Analysis of the Model

557 Supplementary Master Equation for Gene Activation

558 Supplementary Introduction to Nonlinear Dynamics

\section{References}

560 1. Diaz, J. SARS-CoV-2 Molecular Network Structure. Front. Physiol. 10 (2020). doi:

561 https://doi.org/10.3389/fphys.2020.00870

562 2. McBride, R., and Fielding, B.C. The Role of Severe Acute Respiratory Syndrome (SARS)-

563 Coronavirus Accessory Proteins in Virus Pathogenesis. Viruses 4, 2902-2923 (2012).

564 doi:10.3390/v4112902

565 3. Gordon, D. E. et al. A SARS-CoV-2-Human Protein-Protein Interaction Map Reveals Drug

566 Targets and Potential Drug-Repurposing. BioRxiv preprint. (2020). doi:

567 https://doi.org/10.1101/2020.03.22.002386

568 4. Hamming, I. et al. Tissue distribution of ACE2 protein, the functional receptor for SARS

569 coronavirus. A first step in understanding SARS pathogenesis. J Pathol 203: 631-637 (2004). doi:

570 10.1002/path.1570

571 5. Letko, M. et al. Functional assessment of cell entry and receptor usage for SARS-CoV-2 and

572 other lineage B betacoronaviruses. Nature Microbiology 5:562-569 (2020). doi:

573 https://doi.org/10.1038/s41564-020-0688-y

574 6. Sevajol, M. et al. Insights into RNA synthesis, capping, and proofreading mechanisms of SARS-

575 coronavirus. Virus Research (2014). doi: http://dx.doi.org/10.1016/j.virusres.2014.10.008

576 7. Dongwan, K. et al. The architecture of SARS-CoV-2 transcriptome. BioRxiv preprint (2020).

577 doi: https://doi.org/10.1101/2020.03.12.988865

578 8. Nakagawa, K. et al. Viral and Cellular mRNA Translation in Coronavirus-Infected Cells.

579 Advances in Virus Research, Volume 96 (2016). Elsevier Inc. ISSN 0065-3527. doi:

580 http://dx.doi.org/10.1016/bs.aivir.2016.08.001

581 9. Forster, P. et al. Phylogenetic network analysis of SARS-CoV-2 genomes. PNAS 117: 9241-9243

582 (2020). doi: www.pnas.org/cgi/doi/10.1073/pnas.2004999117 
583 10. Bartlam, M. et al. Structural insights into SARS coronavirus protein. Curr Opin Struct Biol 15:

584 664-6672 (2005). dol: 10.1016/j.sbi.2005.10.004

585 11. Masters, P.S. The Molecular Biology of Coronaviruses. Advances in Virus Research 66, 193586292 (2006). doi: https://doi.org/10.1016/S0065-3527(06)66005-3

587 12. Wu, A. et al. Genome Composition and Divergence of the Novel Coronavirus (2019-nCoV)

588 Originating in China. Cell Host \& Microbe (2020). https://doi.org/10.1016/j.chom.2020.02.001

589 13. Hekman, R.M. et al. Actionable Cytopathogenic Host Responses of Human Alveolar Type 2

590 Cells to SARS-CoV-2. Molecular Cell 80, 1104-1122 (2020). doi:

591 https://doi.org/10.1016/j.molcel.2020.11.028

592 14. Breitling, R. What is systems biology? Frontiers in Physiology 1:9 (2010). doi:

593 10.3389/fphys.2010.00009

594 15. Weinstein, N. et al. A computational model of the endothelial to mesenchymal transition.

595 Frontiers in genetics 11:40 (2020). doi: https://doi.org/10.3389/fgene.2020.00040

596 16. Enciso, J. et al. Dynamical modeling predicts an inflammation-inducible CXCR7+ B cell

597 precursor with potential implications in lymphoid blockage pathologies. PeerJ 8: e9902 (2020).

598 doi: https://doi.org/10.7717/peerj.9902

599 17. Kumar, N. et al. Integrative Network Biology Framework Elucidates Molecular Mechanisms of

600 SARS-CoV-2 Pathogenesis. BioRxiv preprint (2020). doi:

601 https://doi.org/10.1101/2020.04.09.033910

602 18. Wagner, T. et al. Sumoylation of HDAC2 promotes NF- $\kappa B$-dependent gene expression.

603 Oncotarget 6(9): 7123-7135 (2015). doi: 10.18632/oncotarget.3344

604 19. Yan, X. et al. Nucleocapsid protein of SARS-CoV activates the expression of cyclooxygenase-2

605 by binding directly to regulatory elements for nuclear factor-kappa B and CCAAT/enhancer binding

606 protein. Int J Biochem Cell Biol 38: 1417-1428 (2006). doi: 10.1016/j.biocel.2006.02.003.

607 20. Cohen, R. et al. Resilience of the Internet to random breakdowns. Phys. Rev. Lett. 85: 4626

608 (2000). doi: https://doi.org/10.1103/PhysRevLett.85.4626

609 21. Xu, C. et al. Systemic In Silico Screening in Drug Discovery for Coronavirus Disease

610 (COVID-19) with an Online Interactive Web Server. J. Chem. Inf. Model (2020). doi:

611 https://dx.doi.org/10.1021/acs.jcim.0c00821

612 22. Vilar, S., and Isom, D.G. One Year of SARS-CoV-2: How Much Has the Virus Changed?.

613 BioRxiv preprint (2020). doi : https://doi.org/10.1101/2020.12.16.423071:

614 23. Long, Q. et al. Clinical and immunological assessment of asymptomatic SARS-CoV-2

615 infections. Nature Medicine 26: 1200-1204 (2020).

616 24. Rahman, I., and MacNee, W. Role of transcription factors in inflammatory lung diseases.

617 Thorax 53:601-612 (1998). doi: 10.1136/thx.53.7.601 
618 25. Magro, G. SARS-CoV-2 and COVID-19: Is interleukin-6 (IL-6) the 'culprit lesion' of ARDS

619 onset? What is there besides Tocilizumab? SGP130Fc. Cytokine: X 2: 100029 (2020). doi:

620 https://doi.org/10.1016/j.cytox.2020.100029

621 26. Leisman, D.E. et al. Cytokine elevation in severe and critical COVID-19: a rapid systematic 622 review, meta-analysis, and comparison with other inflammatory syndromes. Lancet Respir Med 623 2020; 8: 1233-44 (2020). doi: https://doi.org/10.1016/ S2213-2600(20)30404-5

624 27. Hennighausen, L., and Lee, H.K. Activation of the SARS-CoV-2 receptor Ace2 by cytokines

625 through pan JAK-STAT enhancers. BioRxiv preprint (2020).

626 doi: https://doi.org/10.1101/2020.05.11.089045

627 28. Alexanian, A., and Sorokin, A. Cyclooxygenase 2: protein-protein interactions and 628 posttranslational modifications. Physiol Genomics 49: 667-681 (2017). doi:

629 10.1152/physiolgenomics.00086.2017: 10.1152/physiolgenomics.00086.2017

630 29. Cho, J. et al. Prostaglandin E2 Induces IL-6 and IL-8 Production by the EP Receptors/Akt/NF-

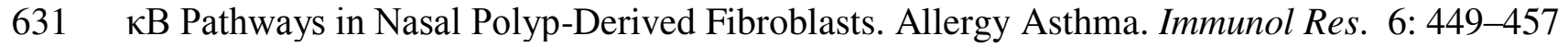

632 (2014). doi: 10.4168/aair.2014.6.5.449

633 30. Bouffi, C. et al. IL-6-Dependent PGE2 Secretion by Mesenchymal Stem Cells Inhibits Local

634 Inflammation in Experimental Arthritis. PLoS ONE 5(12): e14247 (2010).

635 doi:10.1371/journal.pone.0014247

636 31. Wang, L.et al. IL-6 Induces NF-kB Activation in the Intestinal Epithelia. J Immunol 171:31946373201 (2003). doi: 10.4049/jimmunol.171.6.3194

638 32. Newton, R. et al. Repression of Cyclooxygenase-2 and Prostaglandin E2 Release by

639 Dexamethasone Occurs by Transcriptional and Post-transcriptional Mechanisms Involving Loss of

640 Polyadenylated mRNA. The Journal of Biological Chemistry 273: 32312-32321 (1998).

641 doi: $10.1074 /$ jbc.273.48.32312

642 33. Aghai, Z. et al. Dexamethasone suppresses expression of Nuclear Factor-kappaB in the cells of 643 tracheobronchial lavage fluid in premature neonates with respiratory distress. Pediatr Res 59:811-

644815 (2006). doi: 10.1203/01.pdr.0000219120.92049.b3

645 34. Díaz, J. SARS-Cov-2 Systems Biology. Ann Syst Biol 3(1): 029-032 (2020). doi:

646 https://dx.doi.org/10.17352/asb.000009

647 35. Bar-On, Y. et al. SARS-CoV-2 (COVID-19) by the numbers. eLife 9:e57309 (2020). doi: 648 https://doi.org/10.7554/eLife.57309

649 36. Hausser, J. et al. Central dogma rates and the trade-off between precision and economy in gene 650 expression. Nature Communications 10: 68 (2019). doi: https://doi.org/10.1038/s41467-018$651 \quad 07391-8$

652 37. Suleyman, H. et al. Nimesulide is a Selective COX-2 Inhibitory, Atypical Non-Steroidal Anti653 Inflammatory Drug. Current Medicinal Chemistry 15: 278-283 (2008). doi:

$654 \quad 10.2174 / 092986708783497247$ 
655 38. Horby P. et al. Dexamethasone in Hospitalized Patients with Covid-19. The new England

656 Journal of Medicine vol. 384: 693-704 (2021). doi: 10.1056/NEJMoa2021436

657 39. Eftimie, R. et al. Mathematical Models for Immunology: Current State of the Art and Future

658 Research Directions. Bull Math Biol 78:2091-2134 (2016). doi: 10.1007/s11538-016-0214-9

659 40. Morel, P.A. et al. New Insights into Mathematical Modeling of the Immune System.

660 Immunologic Research 36:157-165 (2006). doi: 10.1385/IR:36:1:157

661 41. Cessac, B. A view of Neural Networks as dynamical systems. arXiv: 0901.2203v2 [nlin.AO]

662 (2009). doi: 10.1142/S0218127410026721

663 42. Nayak, S.J. et al. A Review on the Nonlinear Dynamical System Analysis of Electrocardiogram

664 Signal. Journal of Healthcare Engineering Volume 2018, Article ID 6920420 (2018). doi:

665 https://doi.org/10.1155/2018/6920420

666 43. Hodgkin, A.L., and Huxley, A.F. A quantitative description of membrane current and its

667 application to conduction and excitation in nerve. The Journal of Physiology. $117: 500$

66844 (1952). doi:10.1113/jphysiol.1952.sp004764

669 44. El Baba, R., and Herbein, G. Management of epigenomic networks entailed in coronavirus

670 infections and COVID-19. Clin Epigenet 12:118 (2020). doi: https://doi.org/10.1186/s13148-020-

$671 \quad 00912-7$

672 45. Vidya, M.K. et al. Toll-like receptors: Significance, ligands, signaling pathways, and functions

673 in mammals. International Reviews of immunology (2017). doi:

674 https://doi.org/10.1080/08830185.2017.1380200

675 46. Bensussen, A. et al. Dynamics of the Gene Regulatory Network of HIV-1 and the Role of Viral

676 Non-coding RNAs on Latency Reversion Frontiers in Physiology 9:1364 (2018). doi:

677 10.3389/fphys.2018.01364

678 47. Danos, V. et al. Rule-based modelling of cellular signalling. In: CONCUR 2007—concurrency

679 theory. Springer, Berlin, pp 17-41 (2007). doi: 10.1007/978-3-540-74407-8_3

680 48. Martinez-Sanchez, M.E. et al. Role of cytokine combinations on CD4+ T cell differentiation, 681 partial polarization, and plasticity: continuous network modeling approach. Frontiers in Physiology 682 9: 877 (2018). doi: https://doi.org/10.3389/fphys.2018.00877

683 49. Strogatz, S.H. Nonlinear dynamics and chaos with applications to Physics, Biology, Chemistry 684 and Engineering. CRC Press, $2^{\text {nd }}$ Edition (2015). ISBN-13 : 978-0813349107

685 50. Bai, D. et al. Akt-mediated regulation of NFKB and the essentialness of NFkB for the 686 oncogenicity of PI3K and Akt. Int J Cancer. 125:2863-2870 (2009). doi:10.1002/ijc.24748

687 51. Jafarzadeha, A. et al. Contribution of monocytes and macrophages to the local tissue 688 inflammation and cytokine storm in COVID-19: Lessons from SARS and MERS, and potential

689 therapeutic interventions. Life Sciences 257: 118102 (2020). doi:

690 https://doi.org/10.1016/j.lfs.2020.118102 


\begin{tabular}{|c|c|}
\hline Basic Inflammation Circuit & Parameters \\
\hline $\begin{array}{l}\frac{d N F \kappa B}{d t}=V_{n f}^{\max } p_{n f}^{o n}(t)+k_{1} \cdot i l 6 \cdot i \kappa b n f+k_{11} p g e 2 \cdot i \kappa b n f-k_{4} i \kappa b \cdot n f-D \cdot n f \\
i \kappa b n=I \kappa B-N F \kappa B \text { molecular complex }\end{array}$ & $\begin{array}{l}k_{1}=0.5 \mathrm{pg} \mathrm{mL}^{-1} \mathrm{~s}^{-1} \\
k_{4}=5 \mathrm{pg} \mathrm{mL}^{-1} \mathrm{~s}^{-1} \\
D=1 \mathrm{~s}^{-1}\end{array}$ \\
\hline $\begin{array}{l}\frac{d\left(n f^{*}\right)}{d t}=D\left(\frac{V_{c y t}}{V_{n u c}}\right) n f-k_{\mathrm{deg}} n f * \\
n f^{*}=\text { nuclear concentration of } N F \kappa B\end{array}$ & $\begin{array}{l}k_{\text {deg }}=2 \mathrm{~s}^{-1} \\
\left(\frac{V c y t}{V n u c}\right)=2\end{array}$ \\
\hline $\begin{array}{l}\frac{d(i \kappa b n f)}{d t}=k_{4} n f \cdot i \kappa b-k_{5} i l 6 \cdot i \kappa b n f-k_{11} p g e 2 \cdot i \kappa b n f \\
i \kappa b n f=I \kappa B-N F \kappa B \text { molecular complex } \\
p g e 2=\text { amount of PGE2 }\end{array}$ & $\begin{array}{l}k_{4}=5 \mathrm{pg} \mathrm{mL}^{-1} \mathrm{~s}^{-1} \\
k_{5}=0.5 \mathrm{pg} \mathrm{mL}^{-1} \mathrm{~s}^{-1}\end{array}$ \\
\hline $\begin{array}{l}\frac{d p_{I L 6}^{o n}(t)}{d t}=k_{2} \frac{n f^{*}}{h d^{*}+1} p_{I L 6}^{o f f}(t)-k_{-2} p_{I L 6}^{o n}(t) \\
p_{I L 6}^{o n}(t)=\text { probability of } I L 6 \text { activation at time } t \\
h d^{*}=\text { amount of HDAC2 in nucleus }\end{array}$ & $\begin{array}{l}k_{2}=0.1(\text { Number of } \\
\text { Molecules })^{-1} \mathrm{~s}^{-1} \\
k_{-2}=0.035 \mathrm{~s}^{-1}\end{array}$ \\
\hline $\begin{array}{l}\frac{d p_{I \kappa B}^{o n}(t)}{d t}=k_{3} \frac{n f^{*}}{h d^{*}+1}\left(1-p_{I \kappa B}^{o n}(t)\right)-k_{-3} p_{I \kappa B}^{o n}(t) \\
p_{I \kappa B}^{o n}(t)=\text { probability of } I \kappa B \text { activation at time } t\end{array}$ & $\begin{array}{l}k_{3}=0.1(\text { Number of } \\
\text { Molecules })^{-1} \mathrm{~s}^{-1} \\
k_{-3}=0.035 \mathrm{~s}^{-1}\end{array}$ \\
\hline $\begin{array}{l}\frac{d p_{C o x 2}^{o n}(t)}{d t}=k_{7} \frac{n f *}{h d^{*}+1}\left(1-p_{C o x 2}^{o n}(t)\right)-k_{-7} p_{C o x 2}^{o n}(t) \\
p_{C o x 2}^{o n}(t)=\text { probability of Cox2 activation at time } t\end{array}$ & $\begin{array}{l}k_{7}=0.1(\text { Number of } \\
\text { Molecules })^{-1} \mathrm{~s}^{-1} \\
k_{-7}=0.035 \mathrm{~s}^{-1}\end{array}$ \\
\hline $\begin{array}{l}\frac{d p_{N F \kappa B}^{o n}(t)}{d t}=k_{15} \frac{n f^{*}}{h d^{*}+1}\left(1-p_{N F \kappa B}^{o n}(t)\right)-k_{-15} p_{N F \kappa B}^{o n}(t) \\
p_{N F \kappa B}^{o n}(t)=\text { probability of } N F \kappa B \text { activation at time } t\end{array}$ & $\begin{array}{l}k_{15}=0.1\left(\text { Num }^{-1} \text { of }\right. \\
\text { Molecules })^{-1} \mathrm{~s}^{-1} \\
k_{-15}=0.035 \mathrm{~s}^{-1}\end{array}$ \\
\hline $\begin{array}{l}\frac{d(n s p 5)}{d t}=\phi-k_{18} n s p 5 \\
n s p 5=\text { amount of viral Nsp5 in cell } \\
\phi=\text { rate of Nsp5 production }\end{array}$ & $\begin{array}{l}k_{18}=0.7 \mathrm{~s}^{-1} \\
\phi=14 \mathrm{pg} \mathrm{mL}^{-1} \mathrm{~s}^{-1}\end{array}$ \\
\hline
\end{tabular}


Nsp5 and lung inflammation

\begin{tabular}{|c|c|}
\hline $\begin{array}{l}\frac{d(h d)}{d t}=\frac{r}{n s p 5+1}-D_{2} \cdot h d \\
h d=\text { amount of HDAC2 in cytoplasm } \\
D_{2}=\text { transport constant of HDAC2 }\end{array}$ & $\begin{array}{l}r=30 \mathrm{pg} \mathrm{mL}^{-1} \mathrm{~s}^{-1} \\
D_{2}=2 \mathrm{~s}^{-1} \\
\eta=1 \mathrm{pg} \mathrm{mL}^{-1}\end{array}$ \\
\hline$\frac{d\left(h d^{*}\right)}{d t}=D_{2}\left(\frac{V_{c y t}}{V_{n}}\right) h d-k_{\operatorname{deg} 2} h d^{*}$ & $\begin{array}{l}D_{2}=2 s^{-1} \\
k_{\text {deg } 2}=2 \mathrm{~s}^{-1} \\
\left(\frac{V c y t}{V n u c}\right)=2\end{array}$ \\
\hline$\frac{d(i l 6)}{d t}=\alpha(t)+V_{I L 6}^{\max } p_{I L 6}^{o n}(t)-k_{5} \cdot i l 6 \cdot i \kappa b n f-k_{6} i l 6$ & $\begin{array}{l}k_{5}=0.5 \mathrm{pg} \mathrm{mL}^{-1} \mathrm{~s}^{-1} \\
k_{6}=0.5 \mathrm{~s}^{-1} \\
\alpha(t)=10 \mathrm{pg} \mathrm{mL}^{-1} \mathrm{~s}^{-1}\end{array}$ \\
\hline$\frac{d(i \kappa b)}{d t}=V_{I \kappa B}^{\max } p_{I \kappa B}^{o n}(t)-k_{4} i \kappa b \cdot n f$ & $k_{4}=5 \mathrm{pg} \mathrm{mL}^{-1} \mathrm{~s}^{-1}$ \\
\hline$\frac{d(\operatorname{cox} 2)}{d t}=V_{\operatorname{Cox} 2}^{\max } p_{\operatorname{Cox} 2}^{o n}(t)-k_{10} \operatorname{cox} 2$ & $k_{10}=0.4 \mathrm{~s}^{-1}$ \\
\hline$\frac{d(p g e 2)}{d t}=k_{17} \operatorname{cox} 2-k_{11} p g e 2 \cdot i \kappa b n f-k_{12} p g e 2$ & $\begin{array}{l}k_{17}=0.8 \mathrm{~s}^{-1} \\
k_{11}=0.8 \mathrm{pg} \mathrm{mL}^{-1} \mathrm{~s}^{-1} \\
k_{12}=3 \mathrm{~s}^{-1}\end{array}$ \\
\hline
\end{tabular}

694

In the reference state the translation velocities are: $V_{n f}^{\max }=V_{C o x 2}^{\max }=V_{I L 6}^{\max }=V_{I \kappa B}^{\max }=2 \mathrm{pg} \mathrm{mL}^{-1} \mathrm{~s}^{-1}$

697

698

699

700

701

702

703

704

705

706

707

708

709

710

711

712

713

714

715 


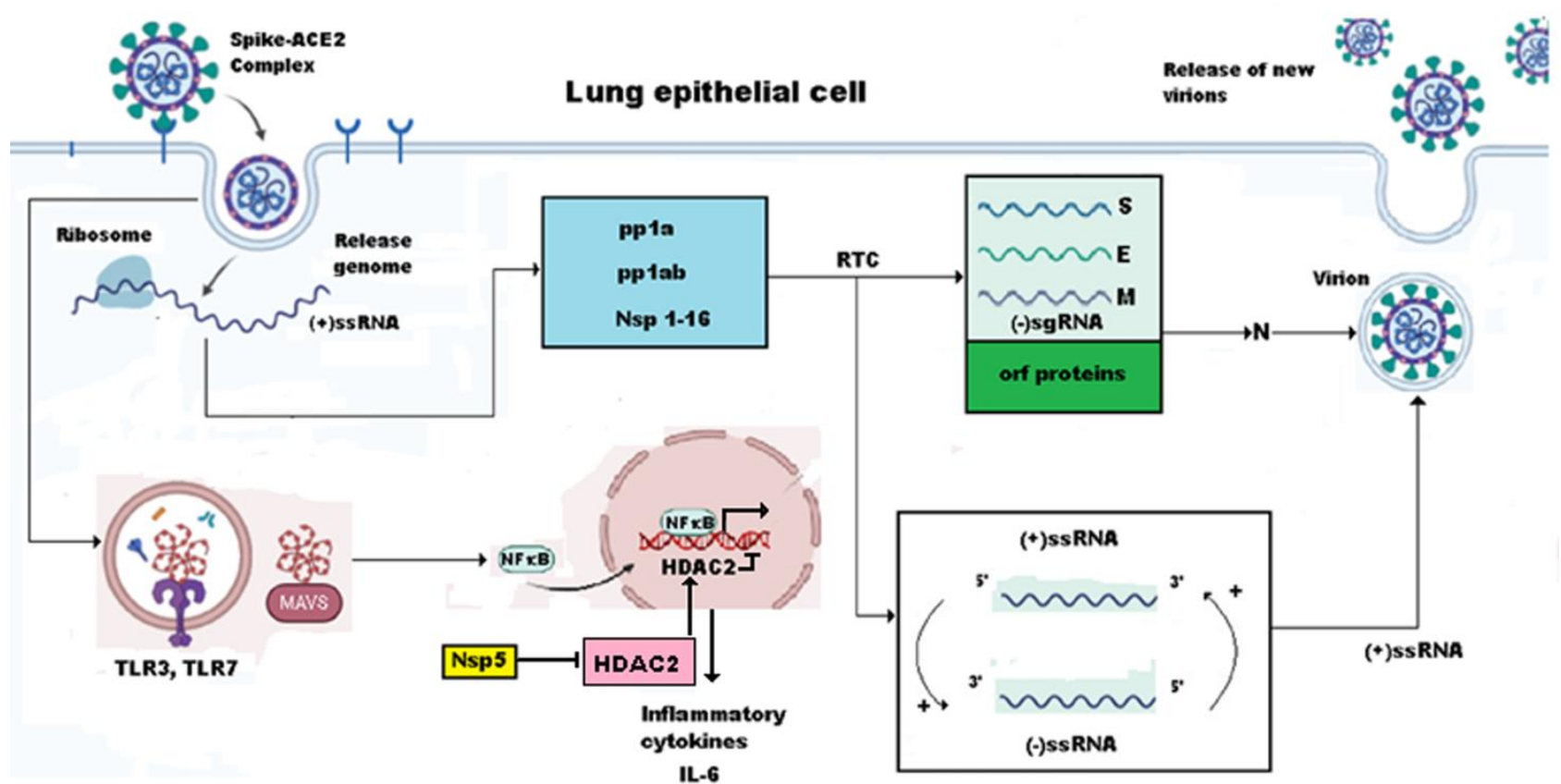

Figure 1.- Process of infection of lung cells by SARS-CoV-2. Infection begins when the protein $S$ of the virion binds with high affinity to the cells surface receptor ACE2 (Angiotensin-Converting Enzyme 2) that is highly abundant in the lung alveolar type II cells. The formation of the complex S-ACE2 initiates the process of fusion between the virion envelope and the cells membrane leading to the liberation of the nucleocapside with the viral genome into the cytoplasm .SARS-CoV-2 genome consists of a positive-sense nonsegmented single stranded mRNA $((+)$ ssRNA) of $\sim 30 \mathrm{~kb}$. The open reading frames 1a (orf1a) and 1b (orflb) are located near the 5'UTR of the (+)ssRNA and they code for the polyproteins ppla and pplab. Maturation of these polyproteins results in 11 nonstructural proteins (Nsp) from the orf1a segment (Nsp1 to Nsp11) and 5 nonstructural proteins from the orf1b segment (Nsp12 to Nsp16). Nsp proteins form the replicationtranscription complex (RTC) a set of nested subgenomic minus-strands of RNA ((-)sgRNA) are synthesized in a process of discontinuous transcription. These (-) sgRNAs serve as the templates for the production of subgenomic mRNAs from which the structural proteins $\mathrm{E}, \mathrm{M}, \mathrm{N}$ and $\mathrm{S}$, together with the accessory proteins orf $3 a$, orf6, orf7a, orf7b, orf8, orf9b, orf9c and orf10 are synthesized. The presence of viral (+)ssRNA initiates the TLR3 and TLR4 mediated immune response, which increases the concentration of free NF $\kappa \mathrm{B}$ in cytoplasm. Cytoplasmic NF $\mathrm{\kappa B}$ enters the nucleus where promotes the transcription of a series of target genes. Viral protein Nsp5 inhibits the inhibition exerted by HDAC2 on nuclear NF $\kappa \mathrm{B}$ transcription factor, enhancing the synthesis of inflammatory cytokines like IL-6. (Figure drawn with Biorender template https://app.biorender.com/). 


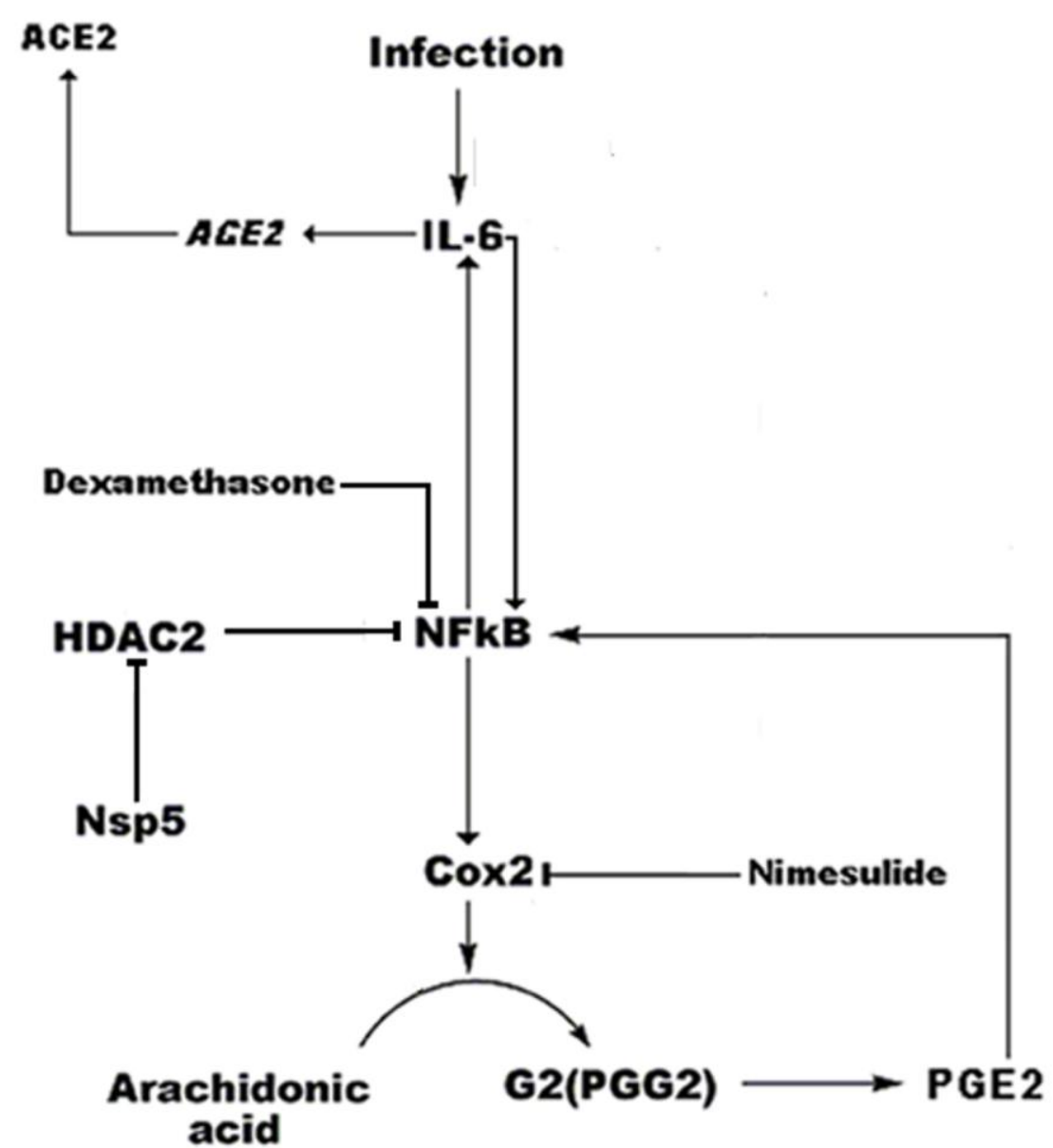

Figure 2.- Circuit representation of inflammation. IL- $6, \mathrm{NF} \kappa \mathrm{B}, \mathrm{Cox} 2$, and PGE2 are the basic nodes of the circuit that represents the basic features of inflammation of lung cells during SARS-CoV-2 infection. In this circuit the arrows represent activation and the bars inhibition. In the figure are shown two positive feedback loops between IL- 6 and NF $\kappa B$, and between NF $\kappa B$ and Cox 2 . IL- 6 also induces the expression of the ACE2 receptor in the lung cell membrane. NF $\kappa B$ is inhibited by HDAC2, which in turn is inhibited by the viral protein Nsp5. The circuit has two targets for the anti-inflammatory drugs Nimesulide and

759 Dexamethasone. 

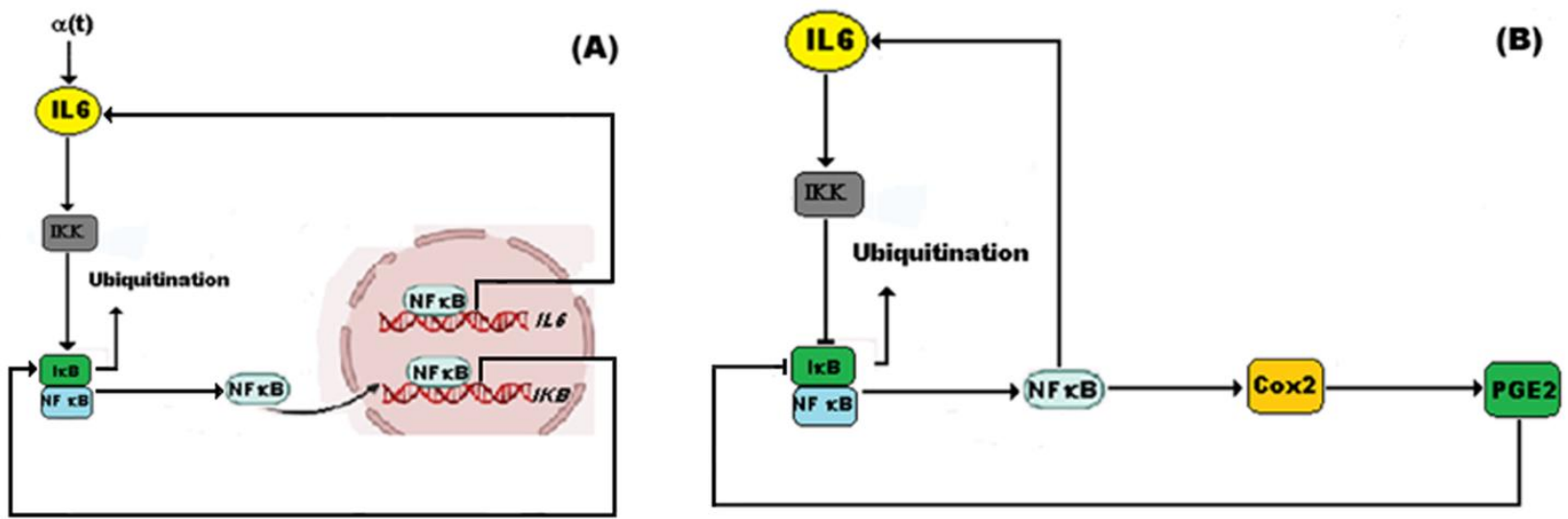

776

777

778

779

780

781

782

783

784

785

786

787

788

789

790

791

792

793

794

795

796

797

798

799

800

801

802

803

804

805
Figure 3.- Feedback loops of the model of inflammation. The mathematical model proposed in this work is based on the dynamical features of three feedback loops: A) two positive feedback loops between IL-6 and

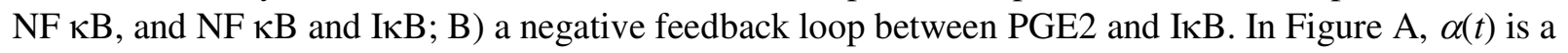
external signal that represents the amount of IL- 6 produced by immune cells like monocytes and lymphocytes, among others. 

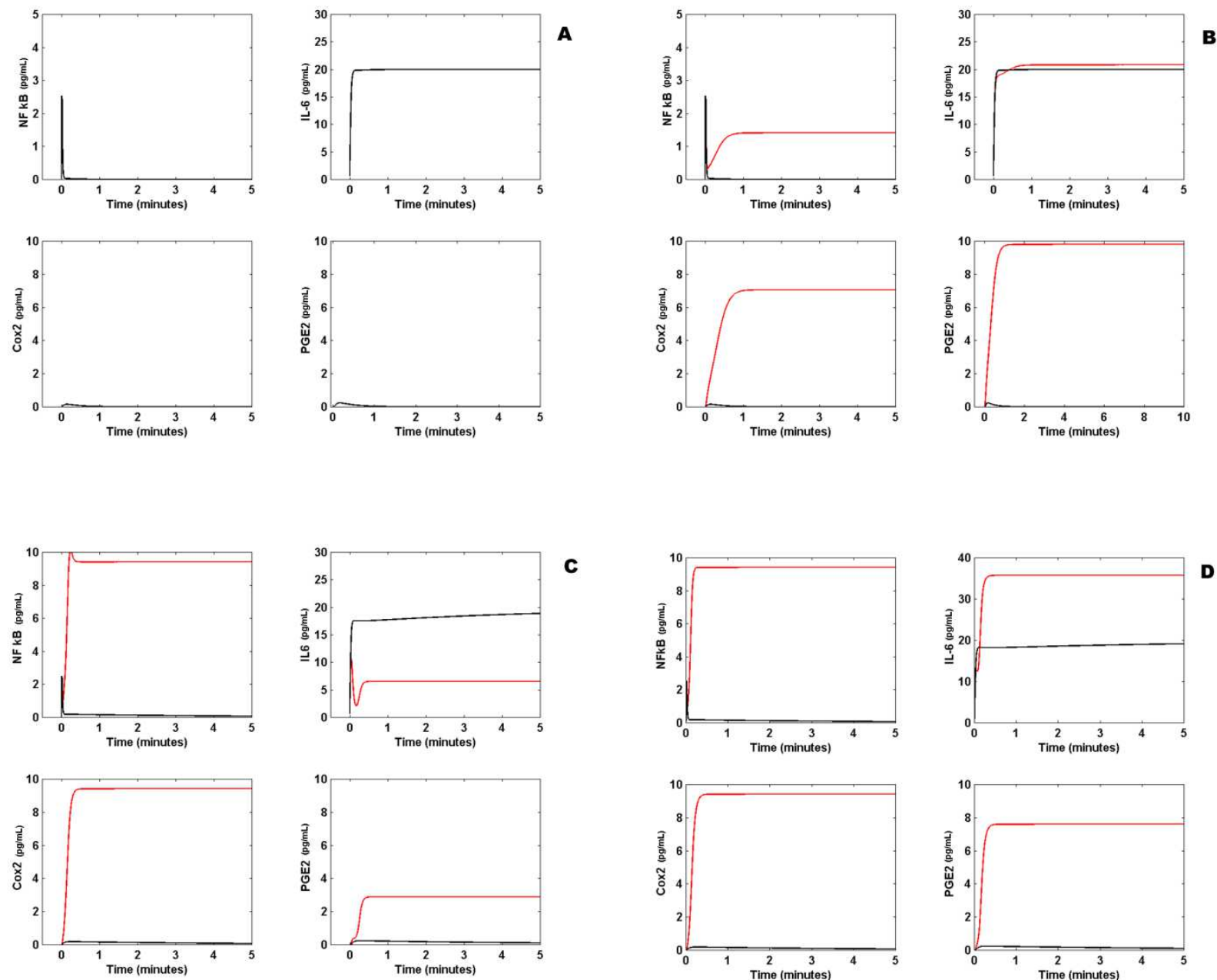

Figure 4.- Effect of Nsp5 on IL-6 production. A) Arbitrary reference state (ARS) of the circuit of Figure 2. In absence of the viral protein Nsp5, the response to an external input $a(t)=10 \mathrm{pg} \mathrm{mL}^{-1} \mathrm{~s}^{-1}$ is a transitory activation of NF $\kappa \mathrm{B}, \mathrm{Cox} 2$, and PGE2. In this case, IL-6 shows a steady high concentration. In this case, all the gene translation rates are set to $2 \mathrm{pg} \mathrm{mL}^{-1} \mathrm{~s}^{-1}$. B) In presence of Nsp5 the circuit shows steady higher concentrations of NF $\kappa \mathrm{B}, \mathrm{Cox} 2$, and PGE2 (red line) with respect to ARS (black line). IL-6 steady

812 concentration (black line) is unaffected by the presence of the viral protein (red line). In this panel, $a(t)=10$

$813 \mathrm{pg} \mathrm{mL}^{-1} \mathrm{~s}^{-1}$, and all the gene translation rates are set to $2 \mathrm{pg} \mathrm{mL}^{-1} \mathrm{~s}^{-1}$. C) When $\mathrm{NF} \kappa \mathrm{B}$ and I $\mathrm{BB}$ translation rates are $V_{n f}^{\max }=10 \mathrm{pg} \mathrm{mL}^{-1} \mathrm{~s}^{-1}$ and $V_{I \kappa B}^{\max }=15 \mathrm{pg} \mathrm{mL}^{-1} \mathrm{~s}^{-1}$, respectively, and Cox 2 and IL-6 translation rates are $2 \mathrm{nM} \mathrm{s}^{-1}$ the circuit shows a weak sustained activation of $\mathrm{NF} \kappa \mathrm{B}$, Cox2, and PGE2 (black line) in response to the external input $\alpha(t)=10 \mathrm{pg} \mathrm{mL}^{-1} \mathrm{~s}^{-1}$ and in absence of Nsp5. In this case, IL-6 steady concentration does not change (black line). In presence of Nsp5 the circuit shows steady higher concentrations of NF $\kappa \mathrm{B}$, Cox2, and PGE2 (red line), although the concentration of IL-6 is lower than is absence of the virus. D) In the over stimulated immune state (OSIS), the presence of Nsp5 produces an

820 enhanced production of NF $\kappa \mathrm{B}$, Cox 2, PGE2 and IL-5 (red lines). This particular state is obtained when $\alpha(t)$

$821=10 \mathrm{pg} \mathrm{mL}^{-1} \mathrm{~s}^{-1}, V_{n f}^{\max }=10 \mathrm{pg} \mathrm{mL}^{-1} \mathrm{~s}^{-1}, V_{I K B}^{\max }=15 \mathrm{pg} \mathrm{mL}^{-1} \mathrm{~s}^{-1}, V_{C o x 2}^{\max }=2 \mathrm{pg} \mathrm{mL}^{-1} \mathrm{~s}^{-1}$, and $V_{I L 6}^{\max }=20 \mathrm{pg} \mathrm{mL}^{-1}$ $\mathrm{s}^{-1}$. 

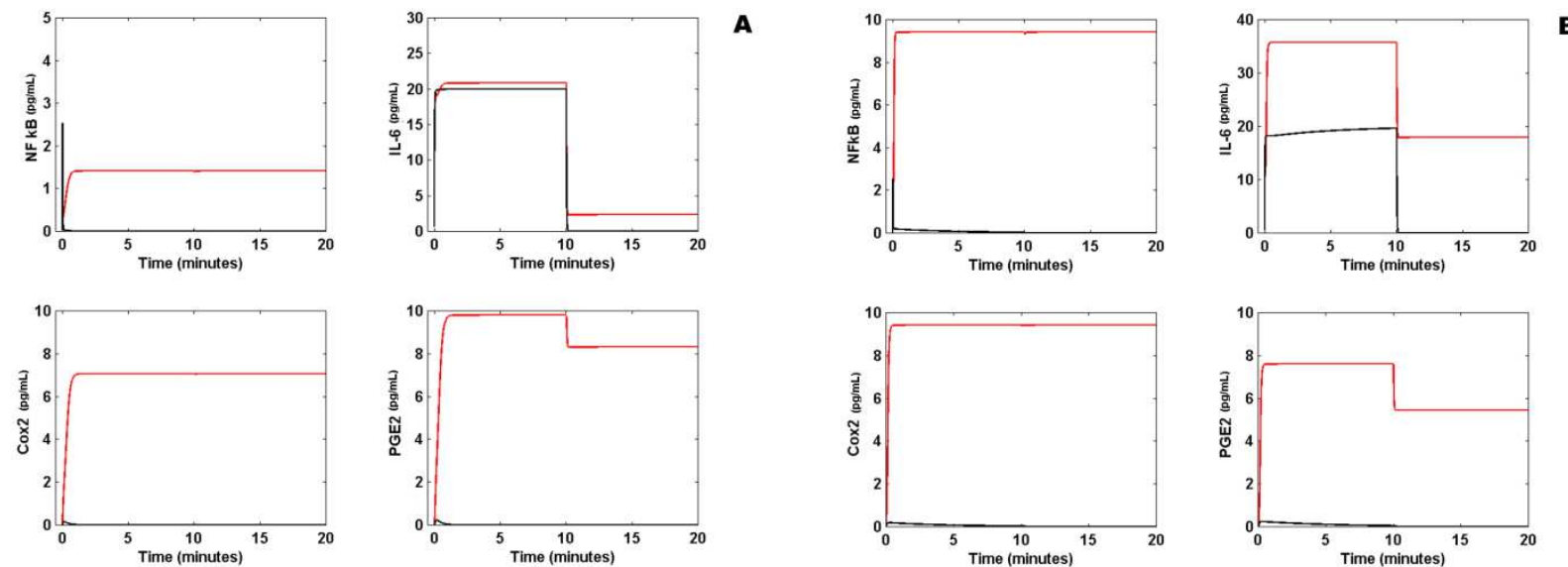

827
Figure 5.- Response of the circuit to a step function. A) When the external signal $\alpha(t)$ is the step function of Eq. (16) of main text and is applied to the ARS in absence of Nsp5 (black line) the level of cytokine IL-6 initially increases to a maximum value of $20 \mathrm{pg} \mathrm{mL}^{-1}$, and becomes zero when the external signal is switched off. There is not any effect on $\mathrm{NF} \kappa \mathrm{B}, \mathrm{Cox} 2$ and PGE2 concentrations in the circuit. However, in presence of Nsp5 (red line) the levels of NF $\kappa \mathrm{B}$, Cox2, PGE2 and IL-6 are increased in response to $\alpha(t)$ and never become zero when the external signal is switched off. B) When the step function of Eq. (16) is applied to the circuit in absence of Nsp5 (black line) with $V_{n f}^{\max }=10 \mathrm{pg} \mathrm{mL}^{-1} \mathrm{~s}^{-1}, V_{I \kappa B}^{\max }=15 \mathrm{pg} \mathrm{mL}^{-1} \mathrm{~s}^{-1}, V_{C o x 2}^{\max }=2 \mathrm{pgmL}^{-1} \mathrm{~s}^{-1}$ and $V_{I L 6}^{\max }=20 \mathrm{pg} \mathrm{mL}^{-1} \mathrm{~s}^{-1}$, there is a low increase in $\mathrm{NF} \kappa \mathrm{B}, \operatorname{Cox} 2$ and PGE2 concentrations that becomes zero when the external signal is switched off. IL-6 initially increases to a maximum value of $20 \mathrm{pg} \mathrm{mL}{ }^{-1}$, and becomes zero when the external signal is also zero. In contrast, when the circuit is in OSIS in presence of $\mathrm{Nsp} 5$ (red line) the concentrations of NF $\kappa \mathrm{B}$, Cox2, PGE2 and IL-6 are increased in response to $\alpha(t)$ and remain at a high value even the external signal is switched $o f f$. 

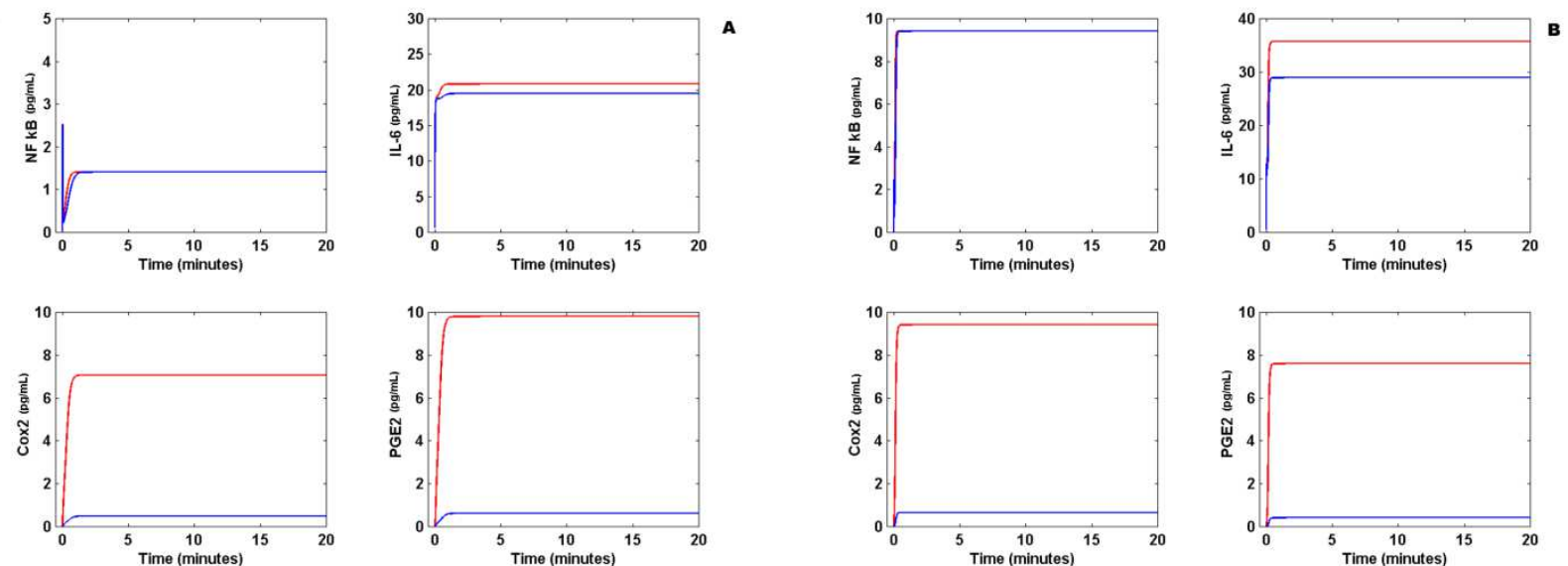

Figure 6.- Effect of Nimesulide on lung cell inflammation. A) Effect of $14 \mathrm{pg} \mathrm{mL}^{-1}$ of

Nimesulide on the levels of NF $\kappa \mathrm{B}$, Cox2, PGE2 and IL-6 when $\alpha(t)=10 \mathrm{pg} \mathrm{mL}^{-1} \mathrm{~s}^{-1}$, and all gene translation rates are $2 \mathrm{pg} \mathrm{mL}^{-1} \mathrm{~s}^{-1}$ in presence of Nsp5 (red line). Nimesulide decreases the concentration of Cox2 and PGE2, but has not effect on NF $\kappa B$ and IL-6 (blue line). B) Effect of $14 \mathrm{pg} \mathrm{mL}^{-1}$ of Nimesulide on the OSIS (red line). Nimesulide significantly decreases the concentration of Cox 2 and PGE2, but has not effect on NF $\kappa B$, The drug has a weak effect on IL-6 concentration (blue line). 

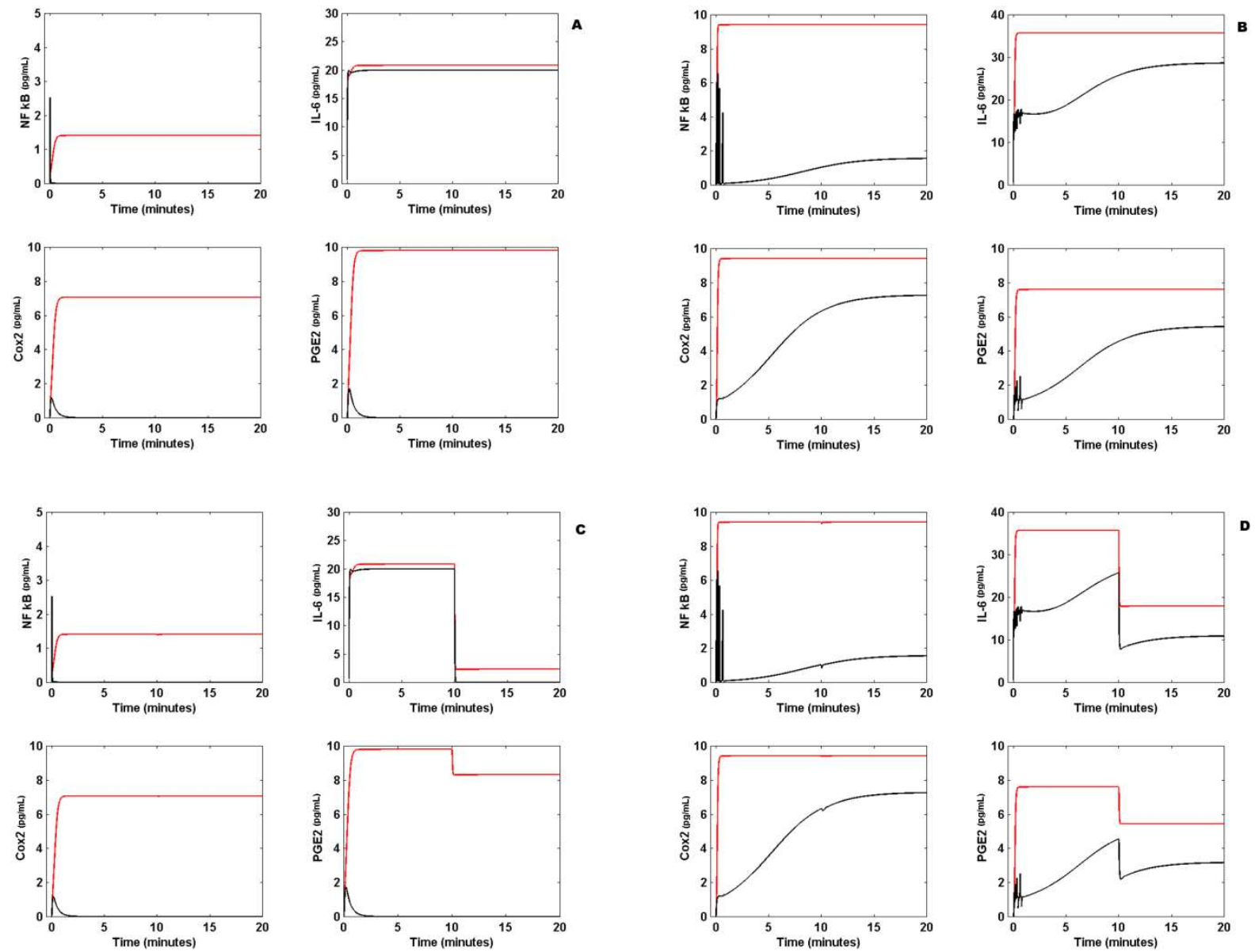

901

902

903

904

905

906

907

908

909

910

911

912

913

914

915

916

917

918

919

920

921

922

923
Figure 7.- Effect of Dexamethasone on lung cell inflammation. A) Effect of $14 \mathrm{pg} \mathrm{mL}^{-1}$ of

Dexamethasone (DX) on the levels of NF $\kappa \mathrm{B}$, Cox2, PGE2 and IL-6 when $a(t)=10 \mathrm{pg} \mathrm{mL}^{-1} \mathrm{~s}^{-1}$, and all gene translation rates are $2 \mathrm{pg} \mathrm{mL}^{-1} \mathrm{~s}^{-1}$ in presence of Nsp5 (red line). DX effectively decreases the concentration of NF $\kappa B$, Cox2 and PGE2 to cero, but has not effect on IL-6 (black line). B) Effect of $14 \mathrm{pg} \mathrm{mL}^{-1}$ of DX on the OSIS (red line). DX has a weak effect on the concentration of NF $\kappa B$, Cox2, PGE2, and IL-6 (red line). C) When the external signal $a(t)$ is the step function of Eq. (16) of main text and is applied to the circuit in presence of $\mathrm{Nsp} 5$ (red line), with all gene translation rates equal to $2 \mathrm{pg} \mathrm{mL}^{-1} \mathrm{~s}^{-1}, 14 \mathrm{pg} \mathrm{mL}^{-1}$ of DX decreases the concentration of NF $\kappa \mathrm{B}$, Cox2, PGE2 and IL-6 to zero (black line). D) When the external signal $a(t)$ is the step function of Eq. (16) of main text and $14 \mathrm{pg} \mathrm{mL}^{-1}$ of DX are applied to the circuit in the OSIS, the drug has a practically null effect on the inflammation process. 

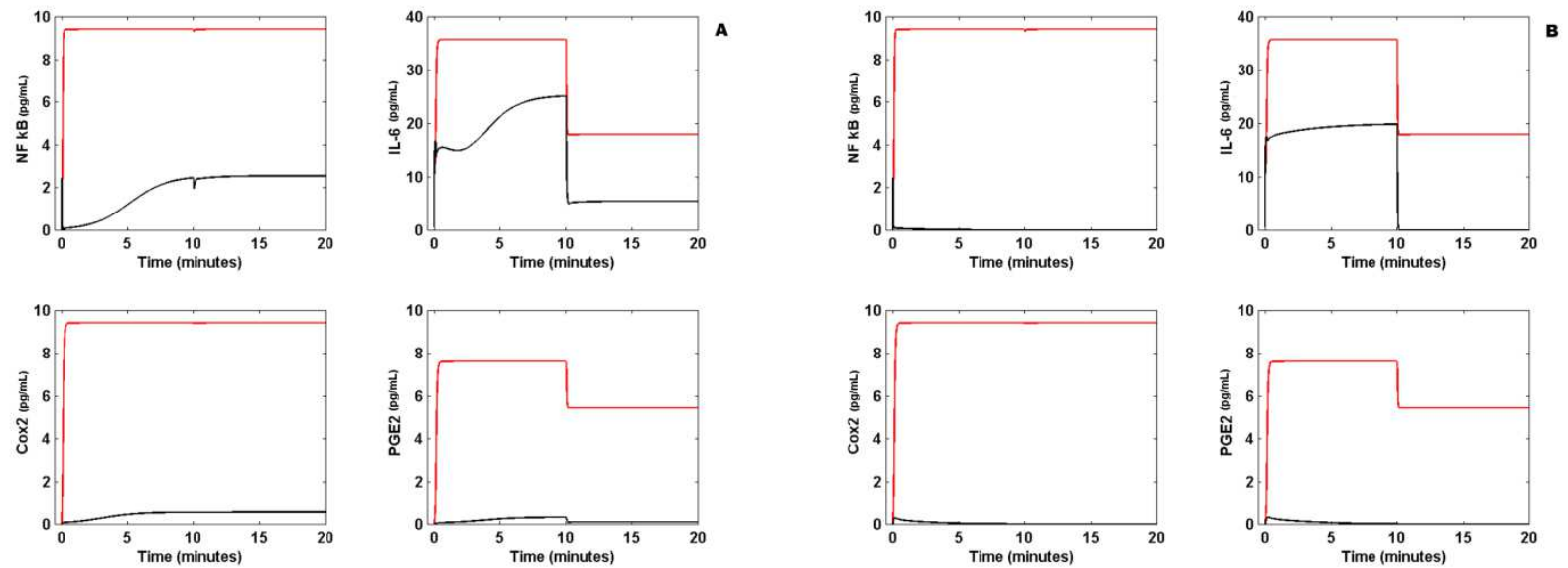

928 Figure 8.- Effect of the molecular docking of Nsp5 on lung inflammation. A) When DX and 929 Nimesulide are applied together (with $35 \mathrm{pg} \mathrm{mL}^{-1}$ of DX and $40 \mathrm{pg} \mathrm{mL}^{-1}$ of Nimesulide) to the circuit 930 in OSIS (red line), in which $\alpha(t)$ is the function of Eq. (16), there is also a little anti-inflammatory 931 effect. B) The molecular docking of Nsp5 completely shuts down the inflammation process when 932 the circuit is in OSIS, with $\alpha(t)$ given by Eq. (16), suggesting that Nsp5 is effectively the cause of 933 the acute lung inflammation during SARS-CoV-2 infection.

934

935

936

937

938

939

940 


\section{Supplementary Files}

This is a list of supplementary files associated with this preprint. Click to download.

- SupplementaryMateriaIABERAJDrevised.pdf 